\title{
Development and validation of a prognostic nomogram for lower-grade glioma based on an autophagy-related IncRNA signature
}

\author{
Type
}

Research paper

\section{Keywords}

glioma, nomogram, long noncoding RNA, autophagy, computational biology

\begin{abstract}
Introduction

Gliomas account for $75 \%$ of the primary malignant brain tumors. The prognosis and treatment planning vary in lower-grade gliomas (LGG) due to their heterogeneous clinical behaviors. The dysregulation of autophagy-related (ATG) IncRNAs plays a crucial role in LGG. We aimed to develop and validate an ATG IncRNA risk signature, and a survival nomogram with integration of novel prognostic for LGG patients.

\section{Material and methods}

Differentially expressed ATG IncRNAs were screened out based on TCGA and GTEx RNA-seq databases. ATG IncRNA prognostic signature was then established by Kaplan-Meier, univariate Cox proportional hazards regression, Least absolute shrinkage and selection operator (LASSO) regression and multivariate Cox proportional hazards regression, with its predictive value validated by time-dependent receiver operating characteristic (ROC) curves. Kaplan-Meier, univariate Cox regression and multivariate Cox proportional hazards regression were used to screen out clinical and molecular variables. A nomogram was developed and internally validated by ROC and calibration plots.
\end{abstract}

\section{Results}

An ATG IncRNA risk signature was constructed with six differentially expressed IncRNAs (LINC00599, LINC02609, AC021739.2, AL118505.1, AL354892.2, and AL590666.2). Based on the risk signature, a nomogram was developed by addition of the significant prognostic clinical variables (age and grade) and molecular variables (IDH status and MGMT status).

\section{Conclusions}

We identified an ATG IncRNA risk signature and develop a nomogram for individualized survival prediction in LGG patients. A user-friendly free online calculator to facilitate the use of this nomogram among clinicians is also provided: https://linstu2009.shinyapps.io/LGGPRODICTORapp/?_ga=2.3154 800.1506830296.1588641469-159983587.1588641469. 
Development and validation of a prognostic nomogram for lower-grade glioma based on an autophagy-related IncRNA signature

Running title: lncRNA-based nomogram in lower-grade gliomas 


\section{Abstract}

Introduction: Gliomas account for $75 \%$ of the primary malignant brain tumors. The prognosis and treatment planning vary in lower-grade gliomas (LGG) due to their heterogeneous clinical behaviors. The dysregulation of autophagy-related (ATG) lncRNAs plays a crucial role in LGG. We aimed to develop and validate an ATG lncRNA risk signature, and a survival nomogram with integration of novel prognostic for LGG patients.

Material and methods: Differentially expressed ATG lncRNAs were screened out based on TCGA and GTEx RNA-seq databases. ATG lncRNA prognostic signature was then established by Kaplan-Meier, univariate Cox proportional hazards regression, Least absolute shrinkage and selection operator (LASSO) regression and multivariate Cox proportional hazards regression, with its predictive value validated by time-dependent receiver operating characteristic (ROC) curves. Kaplan-Meier, univariate Cox regression and multivariate Cox proportional hazards regression were used to screen out clinical and molecular variables. A nomogram was developed and internally validated by ROC and calibration plots.

Results: An ATG lncRNA risk signature was constructed with six differentially expressed IncRNAs (LINC00599, LINC02609, AC021739.2, AL118505.1，AL354892.2, and AL590666.2). Based on the risk signature, a nomogram was developed by addition of the significant prognostic clinical variables (age and grade) and molecular variables (IDH status and MGMT status).

Conclusions: We identified an ATG lncRNA risk signature and develop a nomogram for individualized survival prediction in LGG patients. A user-friendly free online calculator to facilitate the use of this nomogram among clinicians is also provided: 
https://linstu2009.shinyapps.io/LGGPRODICTORapp/?_ga=2.3154800.1506830296.158864 1469-159983587.1588641469.

Keywords: glioma; autophagy; long noncoding RNA; nomogram; computational biology

\section{Introduction}

Gliomas account for $75 \%$ of primary malignant brain tumors in adults and are associated with high mortality $(1,2)$. Lower-grade gliomas (LGGs), including diffuse low-grade and intermediate-grade gliomas (World Health Organization (WHO) grades II and III), show a considerably high morbidity $(3,4)$. Despite a rarer incidence and overall better prognosis for LGG than grade IV tumors and glioblastoma (GBM), 70\% of LGGs can develop into GBM and lead to the death of patients within 10 years (5). Molecular alterations, which can be identified objectively, are now believed to serve as more important prognostic factors than histologic grading (3). The current gold standard treatment of glioma includes surgical resection followed by radiotherapy and chemotherapy (6). However, due to the heterogeneity of their clinical behaviors, the standard care of LGG has been debated, thus presenting a therapeutic challenge to physicians $(4,7)$. Therefore, searching for novel biomarkers for survival prediction and individualized treatment planning to improve the outcomes of LGG patients is necessary and urgent.

Induced by diverse cellular stresses, macroautophagy (autophagy hereafter) is a self-digestive process involving the formation and turnover of autophagosomes, which engulf cellular proteins and organelles for delivery to lysosomes. Unlike apoptosis that represents canonical type I programmed cell death, autophagy is a "double-edged sword", as it can contribute to 
stability, survival and evasion of stress, where it is often referred to as "protective autophagy", as well as being toxic by promoting type II cell death $(8,9)$. These processes are regulated by evolutionarily conserved autophagy-related (ATG) genes $(10,11)$. The deregulation of ATG genes results in abnormal autophagy and is associated with a variety of pathological conditions, including cancer (12), with accumulating evidence demonstrating that autophagy is involved in the activities of glioma $(7,13)$. Specifically, long noncoding RNAs (lncRNAs), which are transcripts longer than 200 nucleotides (nt) without protein-coding capacity (14, 15), have been reported to regulate autophagy activity by changing the transcript levels of ATG genes $(16,17)$. Acting individually or cooperatively as competitive platforms for both miRNAs and mRNAs, lncRNAs are crucial regulators of ATG genes in autophagy regulatory networks $(16,18)$. For instance, the lncRNA PTENP1 induced cellular autophagy and apoptosis by decoying several ATG-targeting miRNAs, thus repressing the tumorigenic properties of hepatocellular carcinoma (19). Gu et al. revealed that the lncRNA DICER1-AS1 promoted the proliferation, autophagy and invasion of osteosarcoma cells by targeting ATG5 (20). Additionally, the lncRNA MEG3 was revealed to promote cisplatin-induced apoptosis via the inhibition of autophagy in human glioma cells (13). Thus, exploring ATG lncRNAs will be important to provide new insights into prognostic biomarkers and therapeutic interventions for LGG.

A nomogram is a useful and accessible tool for predicting survival and planning individualized treatments by providing an individualized estimate of survival rather than a group prediction (21). Although several nomograms for LGG survival have previously been established, they lack the integration of transcriptome data or a comprehensive inclusion of 
novel prognostic factors. Thus, in this study, we aimed to develop and validate a prognostic nomogram for individualized survival prediction for LGG patients by integrating an ATG lncRNA risk signature with novel clinical and molecular prognostic factors (age, grade, isocitrate dehydrogenase (IDH) status, and O6-methylguanine-DNA methyltransferase (MGMT) status). In addition, a user-friendly online application was developed.

\section{Materials and methods}

\subsection{Clinical data collection and processing}

The study design was shown as a flow chart (Figure. 1). Two public databases, The Cancer Genome Atlas (TCGA) and Genotype-Tissue Expression (GTEx) Project, served as the primary sources of this study. TCGA (dataset ID: TCGA-LGG.htseq_fpkm) provided LGG IncRNA expression profiles as well as corresponding clinical information and molecular parameters, while GTEx (dataset ID: gtex_RSEM_gene_fpkm) offered lncRNA expression profiles of normal brain tissues. Specifically, the RNA sequencing (RNA-seq) expression profiles were downloaded from UCSC Xena (2020.3, https://xena.ucsc.edu/) (22). Clinical information and molecular parameters were downloaded from GlioVis (2020.3, http://gliovis.bioinfo.cnio.es) (23), including the following variables for each patient: tumor grade (grade II or grade III), age at diagnosis ( $>40$ years old or $<40$ years old), sex (male or female), IDH mutation status (IDH-mutant or IDH-wild type), MGMT status (methylated or unmethylated), survival/follow-up time in months (continuous) and survival status (alive or dead). By using data from Ensembl (https://uswest.ensembl.org/index.html) (24), we reannotated the gene symbols and extracted lncRNAs (including sense_overlapping, lincRNA, 
3prime_overlapping_ncrna, processed_transcript, and antisense, sense_intronic (25)) from the original dataset. The lncRNA expression profiles from 529 normal brain samples and 529 LGG samples are presented by $\log 2(\mathrm{fpkm}+1)$. Then, the two datasets were merged into one with normalization by using the "limma" package, version 3.42.0 (http://www.bioconductor.org/) (26) in R language, version 3.6.2 (https://cran.r-project.org/). LncRNAs with an expression value of 0 were removed. Eventually, 14086 lncRNAs among 1058 samples were found.

\subsection{Identification of DEIncRNAs}

Principal component analysis (PCA) by the "stats" package, version 3.6.2 (https://cran.r-project.org/), was used to determine the visualized genetic distance and relatedness between normal brain tissue and LGG. Differentially expressed lncRNAs (DElncRNAs) between LGG and normal brain tissue were generated using the "limma" package. LncRNAs were considered to have statistically significant differences in expression if $\mid \log 2$ (fold-change) $\mid \geq 2$ and false discovery rate $(F D R)<0.05$. We performed hierarchical clustering based on the most variably expressed genes using Euclidean distance as the similarity metric and the complete linkage method as the between-cluster distance metric.

\subsection{Identification of ATG DEIncRNAs}

ATG genes were extracted from the Human Autophagy Database (HADb, http://www.autophagy.lu/index.html) (27). All of the mRNA expression data were normalized by $\log 2$ transformation. Pearson correlation was applied to calculate the 
correlation between the DElncRNAs and ATG genes. A DElncRNA with a correlation coefficient $|\mathrm{r}|>0.4$ and $\mathrm{p}$ value $<0.05$ was considered to be an ATG DElncRNA.

\subsection{Identification of a prognostic ATG IncRNA signature}

Twenty-five LGG samples, in which survival, clinical or molecular subtype information was missing, were excluded. Using the "caret" package, version 6.0-85 (https://cran.r-project.org/) (28) in R language, the ATG DElncRNA profiles were then randomly divided into a training cohort $(\mathrm{n}=252)$ and a validation cohort $(\mathrm{n}=252)$. A survival analysis model was constructed based on the training cohort by the "survival" package, version 3.1-8 (https://cran.r-project.org/) in R language, while the validation cohort was used for model testing. The median expression level of the training cohort was used to split the ATG lncRNAs into high- and low-expression groups, followed by Kaplan-Meier (K-M) survival analysis to assess the survival differences between them. Univariate Cox proportional hazards regression models were used to assess the association between the ATG lncRNAs and the overall survival (OS) of LGG patients from the training cohort. P value $<0.05$ was considered statistically significant. Least absolute shrinkage and selection operator (LASSO) regression, which avoids overfitting of the model in the risk signature according to the best lambda value, was performed to filter out the ATG lncRNAs that were significant in univariate Cox analysis. Subsequently, the joint effect of different covariates was assessed using multivariate Cox proportional hazards regression by the "step" function in R programming language, with results shown as forest plots. The relationships among the six 
ATG lncRNAs and their coexpressed ATG genes were displayed by creating a Sankey diagram.

The prognostic prediction model was constructed based on the regression coefficient-weighted lncRNA expression, and a risk score formula was established as follows:

Risk score $=\sum_{i=1}^{n}$ Expi $\times$ Coei

In the formula, $\mathrm{N}$ is the number of selected ATG lncRNAs, with Expi being the expression value of each ATG lncRNA and Coei being the multivariate Cox regression coefficient. Next, the expression profile data of the corresponding ATG IncRNAs were extracted from the training cohort and substituted into the model to calculate the risk score of each patient. The patients were divided into high- and low-risk groups according to the median risk score value. K-M survival analysis was used to estimate the survival distributions. Receiver operating characteristic (ROC) analysis ("survivalROC” package, version 1.0.3, https://cran.r-project.org/) of the ATG lncRNA risk signature for predicting 1-, 3- and 5-year survival was carried out. Replication was carried out to internally validate the model by using the data from the validation cohort.

\subsection{Functional enrichment analysis}

Gene set enrichment analysis (GSEA, https://www.broad institute.org/gsea/index.jsp) was applied to identify the biological functions and pathways between the high- and low-risk groups based on the risk signature. Gene Ontology (GO) and Kyoto Encyclopedia of Genes and Genomes (KEGG) pathways associated with the risk signature were further explored. 
According to the GSEA website, an FDR of 0.25 is reasonable in the setting of exploratory discovery for the validation of the candidate hypothesis in future research, while a more stringent FDR may lead to overlooking potentially significant results. Thus, gene sets with an FDR $<0.25$ in the high- and low-risk groups in the TCGA data set (TCGA-LGG.htseq_fpkm) were considered significantly different and were selected.

\subsection{Development of a prognostic nomogram}

In the training cohort, K-M survival analysis was first used to estimate the survival distributions of each clinical and molecular factor, followed by assessing the association between the OS and each factor using univariate Cox proportional hazards regression models. Next, the joint effect of different covariates was assessed using multivariate Cox proportional hazards regression by the "step" function in the R programming language. The results of both univariate Cox and multivariate Cox analyses are shown as forest plots. Receiver operating characteristic (ROC) analysis ("survivalROC” package) of the ATG lncRNA risk signature, as well as each clinical and molecular factor mentioned above for predicting the 1-, 3- and 5-year survival, was performed to evaluate the sensitivity and specificity of survival prediction. Nonsignificant variables ( $\mathrm{p}$ value $>0.05$ ) were omitted. A nomogram was constructed based on the significant factors for predicting the survival of LGG patients. The survival ROC curve and calibration curve were used to assess the performance of the nomogram. The nomogram was internally validated using the validation cohort. To facilitate clinical use, a free online calculator for the final nomogram was established by the "DEnorm" 
package (version 5.0.1, https://cran.r-project.org/) and published in "https://www.shinyapps.io/".

\subsection{Statistical analysis}

The R programming language (version 3.6.2) was used to perform statistical analyses, including PCA, K-M survival analyses, univariate and multivariate Cox regression models, LASSO regression and ROC curve analysis, as well as to draw figures, including heatmaps, boxplots, forest plots and calibration plots. Quantitative data are shown as the mean \pm standard deviation (SD). Statistical differences between two groups were compared by the Wilcoxon test. A P value $<0.05$ was considered statistically significant.

\section{Results}

\subsection{Construction of a risk signature including six ATG DEIncRNAs}

To graphically determine the distribution of all 14086 lncRNAs within normal brain tissue and LGG, PCA was employed to show that the data had been normalized well and that the variation in the data were maximal (Figure 2a). Subsequently, 112 DElncRNAs with an expression ratio that differed between LGG and normal brain tissues by a factor of at least 2-fold were selected (Figure 2b and 2c). Each lncRNA with their median expression levels in LGG and normal brain tissues is shown in Figure 2d. A total of 232 ATG genes were downloaded from HADb, and 20 ATG DElncRNAs with Pearson correlation coefficient $|r|>0.4$ and $p$ value $<0.05$ were selected (Figure $2 \mathrm{e}$ ). LGG patients in the TCGA dataset with detailed clinical information (age, grade, and gender) and molecular parameters (IDH status 
and MGMT status) were randomly divided into a training cohort $(\mathrm{n}=252)$ and a validation cohort $(\mathrm{n}=252)$ (Table 1). Twelve ATG DElncRNAs of prognostic value were screened out by performing Kaplan-Meier analysis and univariate Cox analysis in the training cohort (Table S1). To select appropriate parameters for constructing a risk signature, LASSO regression was used and identified 10 ATG DElncRNAs (AC021739.2, AC093010.3, AL118505.1, AL121827.2, AL354892.2, AL355916.2, AL590666.2, LINC00599, LINC02609, and NEAT1) (Figures 3a and 3b). Eventually, only 6 ATG DElncRNAs (AC021739.2, AL118505.1, AL354892.2, AL590666.2, LINC00599, and LINC02609) remained following multivariate Cox regression analysis. AC021739.2, AL118505.1, AL354892.2, LINC00599, and LINC02609 were regarded as protective factors (hazard ratios (HRs) < 1), while AL590666.2 was the only risk factor (HR > 1) among these lncRNAs in LGG (Figure 3c). According to the HRs, a Sankey diagram was constructed to intuitively display the regulation of the six ATG lncRNAs on their coexpression genes, with five lncRNAs as protective factors and one as a risk lncRNA (Figure S1). Based on both univariate and multivariate Cox regression analyses, the six lncRNAs as novel prognostic biomarkers were suggested for further analysis.

\subsection{Construction of the prognostic risk signature with six ATG IncRNAs in}

\section{LGG}

The six ATG lncRNAs (AC021739.2, AL118505.1, AL354892.2, AL590666.2, LINC00599, and LINC02609) were incorporated to develop a risk signature in the training cohort. The risk scores were produced using the formula mentioned in the methods as follows: risk 
score $=(-0.3899 \times$ expression level of AC021739.2) $+(-0.5685 \times$ expression level of AL118505.1) $+(-0.7595 \times$ expression level of AL354892.2) $+(-0.2849 \times$ expression level of LINC00599) $+(-0.3508 \times$ expression level of LINC02609) $+(0.5524 \times$ expression level of AL590666.2). The samples in the training cohort were divided into high- and low-risk groups according to the median risk score. As shown in Figure 4a, higher risk scores suggested more deaths. In addition, along with the increasing risk scores, the expression levels of AC021739.2, AL118505.1, AL354892.2, LINC00599, and LINC02609 were decreased, whereas the expression level of AL590666.2 was increased. The K-M curve showed that the high-risk group was associated with poorer prognosis (Figure $4 \mathrm{~b}$ ). The ROC curve was used to evaluate the efficacy of the ATG lncRNA risk signature to predict 1-, 3-, and 5-year survival in LGG patients. The areas under the curve (AUCs) for 1-, 3-, and 5-year survival were $0.788,0.857$, and 0.687 , respectively (Figure $4 c-4 e$ ), indicating that the risk signature had good predictive performance.

\subsection{Validation of the prognostic ATG IncRNA risk signature}

The performance of the ATG lncRNA risk signature was internally tested in the validation cohort. The LGG samples in the validation cohort were divided into high- and low-risk groups according to the median risk score. In line with the results in the training cohort, downregulated expression levels of AC021739.2, AL118505.1, AL354892.2, LINC00599 and LINC02609, as well as upregulated expression of AL590666.2 and more deaths, were observed with higher risk scores (Figure 5a). Similarly, the K-M curve showed that patients in the high-risk group had a relatively unfavorable prognosis (Figure 5b). The AUCs for 1-, 
3-, and 5-year survival were $0.906,0.78$, and 0.725 , respectively (Figure $5 c-5 e$ ), thereby confirming the good predictive efficacy of the risk signature.

\subsection{Functional annotation and signaling pathway enrichment of the ATG IncRNA prognostic signature}

GSEA was conducted to explore the biological functions and pathways associated with the ATG lncRNA risk signature in LGG patients. As a result, a total of 3373 GO functions were enriched in the high-risk group (FDR $<0.25$, top 100 shown in Table S2), including autophagosomes, cell matrix adhesion and regulation of cell junction assembly functions $($ FDR < 0.05) (Figure S2a- S2c), while 181 GO functions were enriched in the low-risk group $($ FDR $<0.25)$ (Table S3), including ribosome assembly functions $($ FDR $<0.05)($ Figure S2d). We also obtained 113 enriched KEGG pathways in the high-risk group (FDR<0.25) (Table S4), including the regulation of autophagy, MAPK signaling pathway, and extracellular matrix $(\mathrm{ECM})$ receptor interaction pathway $(\mathrm{FDR}<0.05)$ (Figure S2e- S2g). For the low-risk group, 6 enriched KEGG pathways are shown in Table S5, including the ribosome pathway $(\mathrm{FDR}<0.25)$ (Figure $\mathrm{S} 2 \mathrm{~h})$.

\subsection{Development and independent validation of a nomogram integrating the risk signature with clinical and molecular variables}

The prognostic significance of clinical factors such as age, gender, and grade, as well as molecular parameters such as IDH status and MGMT status, were previously reported in glioma $(3,29-33)$. In the training cohort, the association of overall survival with these 
variables was assessed using K-M survival analysis (Figure 6a-6e) and Cox proportional hazards regression in univariate and multivariable models (Figure $6 \mathrm{f}$ and $6 \mathrm{~g}$ ). The gender variation was eliminated from the models since the univariate analysis result showed no statistical significance between groups. ROC curves were also used to evaluate the prognostic accuracy of the risk signature and each variable. Due to space limitations, as well as the most commonly used indexes in clinical practice, we only show the predicted 1-, 3-, and 5-year survival rates for LGG patients. As shown in the ROC curves, the AUCs of the ATG lncRNA risk signature for predicting 1-, 3- and 5-year survival were 0.824 (Figure 6i), 0.901 (Figure 6j) and 0.700 (Figure 6k), respectively, which were higher than those of any clinical or molecular variables, except for that of IDH status in 1-year survival (0.867). Conclusively, the ATG lncRNA risk signature provided a more accurate survival prediction than other prognostic factors (age, grade, IDH status, and MGMT status), though they were contributing factors of survival and had good prognostic accuracy. Thus, a nomogram was developed by integrating the ATG lncRNA risk signature with novel prognostic clinical and molecular factors (age, grade, IDH status, and MGMT status). As shown in the nomogram, the probabilities of 1-, 3-, and 5-year survival could be quickly estimated as the total points by adding the points in each item (Figure 6h). ROC curves and calibration plots were used to evaluate the performance of the nomogram. The AUCs of the ROC curves for predicting 1-, 3- and 5-year survival were $0.877,0.937$ and 0.826 , respectively, in the training cohort (Figure 7a) and $0.905,0.914$ and 0.732 in the validation cohort (Figure 7e). The calibration curves showed good agreement between the predictions and observations in the training cohort (Figure 7b-7d) and the validation cohort (Figure 7f-7h) for the probabilities of 1-, 3- 
and 5-year survival. Considering that predictions for other time points are also important, free online software, established by the "DEnorm" package, for the developed nomogram was made available for easier clinical use:

https://linstu2009.shinyapps.io/LGGPRODICTORapp/?_ga=2.3154800.1506830296.158864

$1469-159983587.1588641469$.

\section{Discussion}

A recently published study had confirmed the involvement of aberrant expression of lncRNAs in glioma development by examining the lncRNA profiles from tumor and peritumoral tissues, without exploring the potential contribution of lncRNA expression to patients' survival (34). In our study, we identified six ATG lncRNAs (LINC00599, LINC02609, AC021739.2, AL118505.1, AL354892.2 and AL590666.2) that were of predictive value in LGG survival. Long intergenic nonprotein coding RNA 599 (LINC00599), also known as retinal noncoding RNA3, is located on human chromosome $8 \mathrm{p} 23$ and was first reported to be dynamically expressed during mouse retinal development (35). It is considered to regulate the differentiation of neurons and oligodendrocytes (36) and is now increasingly recognized as a critical player in a variety of cancers and considered an oncogene. For example, LINC00599 promotes the progression of both prostatic cancer and colorectal cancer (37). However, the functional roles of LINC00599 in glioma are controversial. Increased expression of LINC00599 was observed in glioma tissues and cell lines, where its silencing suppressed proliferation and invasion and induced cell cycle arrest involving the Akt/GSK3 $\beta$ pathway $(38,39)$. In contrast, it has been reported that LINC00599 is downregulated in GBM 
cells, and its overexpression inhibits proliferation and induces apoptosis through the miR185- 5p/KLF16 axis (40). In addition, Fu and colleagues revealed that the expression of LINC00599 was reduced in both LGG and GBM tissues and that it served as a tumor-suppressing lncRNA by inhibiting cell migration and invasion through the regulation of the EMT process (41). This finding is in agreement with the concept that LINC00599 is downregulated in LGG and serves as a protective factor for LGG survival. Despite accumulating studies on the molecular mechanisms of lncRNAs, knowledge of the remaining 5 lncRNAs (LINC02609, AC021739.2, AL118505.1, AL354892.2, and AL590666.2) is limited so far. In our study, we show that LINC02609, AC021739.2, AL118505.1 and AL354892.2 all have an HR $<1$, indicating that they are positive predictors of LGG. Conversely, higher expression of AL590666.2 suggests an unfavorable prognosis in LGG. Therefore, these lncRNAs can be further explored for their potential roles in regulating autophagy and as prognostic markers and therapeutic targets of LGG. In addition, GSEA suggested that the ATG lncRNA risk signature was mainly related to autophagy and cell matrix adhesion, which was reported to be involved in the malignant transformation and local invasiveness of glioma cells (42), indicating the essential roles of our signature. By integrating a set of novel prognostic factors, nomograms are useful and accessible tools for predicting survival and individualized treatment planning since they provide an individualized estimate of survival rather than a group prediction (21). Several nomograms for LGG patient survival have been established previously $(4,43,44)$. Among these, the nomogram developed by Gittleman et al. represented the most comprehensive nomogram, including common essential prognostic variables such as sex, tumor grade, and age, as well 
as some critical newly discovered factors including molecular subtype (IDH mutation, 1p/19q codeletion) and Karnofsky performance status (KPS) (4). Our nomogram included all the variables in Gittleman's nomogram, except for postoperative KPS, 1p/19q codeletion and sex. In fact, Gittleman did not identify a sex difference in LGG survival by analyzing data from both TCGA and the Ohio Brain Tumor Study (OBTS) but still kept it in the nomogram considering its clinical significance (4). In line with their results, sex was not statistically significant in our study. According to the published literature, a sex difference was more commonly observed in GBM $(30,45)$, whereas LGG incidence was nearly identical in males and females. Therefore, gender was not included in our nomogram. We did not include the KPS value due to the high amount of missing data in TCGA (up to 55.0\%). Since $1 \mathrm{p} / 19 \mathrm{q}$ codeletion is the most common genetic characteristic of only a specific type of glioma (oligodendroglioma) and is of predictive value in response to chemotherapy and radiation (3, 32, 46), we included IDH mutation status, which is regarded as a hallmark of LGG and characterizes the majority of LGG patients, instead of 1p/19q codeletion $(32,47)$. In addition, we added another important prognostic variable, MGMT status, which is a DNA repair protein correlated with prolonged survival in patients with diffuse gliomas $(3,32,33)$ and was found to be statistically significant in our survival model. Most importantly, we deeply explored the TCGA transcriptome data of LGG tissue rather than simply associating clinical and molecular prognostic factors to establish a lncRNA prognostic signature, which seemed to have the best accuracy among all the prognostic factors according to the AUCs of the ROC curves and was independently validated. A nomogram was developed based on this ATG lncRNA risk signature, with integrations of novel clinical (age and grade) and molecular 
(IDH status and MGMT status) prognostic factors, followed by independent validation demonstrating an accurate and stable performance by ROC curves and calibration plots. This is the first nomogram that comprehensively integrates an ATG lncRNA risk signature with novel clinical and molecular prognostic factors.

An important advantage of this study is the application of transcriptome data from the GTEx Project, which allows access to a much larger data set of normal brain tissue while minimizing measurement bias compared to other studies extracting data from several Gene Expression Omnibus (GEO) datasets. Furthermore, some classical statistical methods were applied to make the survival prediction convincing. First, to avoid overfitting of the model, LASSO regression was used to identify lncRNAs since it allows the model coefficients to become 0 . This property is consistent with our expectation of identified biomarkers in clinical practice in that it is clinically efficient and economical to detect the least number of key biomarkers for diagnosis or prognosis prediction. Second, K-M survival analysis, univariate Cox proportional hazards regression models, multivariate Cox proportional hazards regression, and ROC curves were sequentially used to strictly screen out all potential prognostic factors, with ROC curves and calibration applied for the validation of both the risk signature and nomogram. Third, we internally validated the established risk signature and nomogram in the validation cohort, thereby testing their accuracy in predicting survival. Finally, user-friendly free online software was designed to facilitate the use of the nomogram by clinicians.

However, the present study also has certain limitations. First, our nomogram did not include information regarding treatment, such as the extent of surgical resection, chemotherapy and 
radiotherapy. This is due to the lack of information on the extent of surgical resection in TCGA and the debated standard of care for LGG patients. Second, internal validation was used to evaluate the efficiency of the risk signature and nomogram rather than external validation because of the lack of integrated LGG lncRNA data from other databases, such as GEO. Finally, the validation cohort was based on 252 retrospective datasets from the TCGA database with the application of internal validation instead of external validation to test the accuracy of the risk signature and the nomogram. This is because there is a lack of or too little LGG lncRNA data from other databases, such as GEO, Chinese Glioma Genome Atlas (CGGA), and Repository of Molecular Brain Neoplasia Data (REMBRANDT). However, although we did not include other databases in our research as an external validation, the randomly grouped datasets from the TCGA database used for internal validation were from different institutions. Therefore, the signature is in fact independently validated and is still convincing. Considering all these above limitations, we may replicate our findings in larger cohorts, hopefully with the LGG clinical data bank built, or validate the five-lncRNA signature in future studies when integral datasets are available.

\section{Conclusions}

In conclusion, we complemented available genomic-based studies by identifying six ATG IncRNAs (LINC00599, LINC02609, AC021739.2, AL118505.1, AL354892.2, and AL590666.2) that may serve as potential prognostic biomarkers or therapeutic targets of LGG, followed by establishing of an ATG lncRNA risk signature. With integration of ATG lncRNA risk signature, novel clinical and molecular prognostic factors (age, grade, IDH 
mutation status, and MGMT status), we developed and internally validated a nomogram, thereby providing healthcare practitioners with individualized survival estimates and facilitating treatment planning in LGG patients. To promote the clinical use of this model, a free online software for its implementation is provided as follows:

https://linstu2009.shinyapps.io/LGGPRODICTORapp/?_ga=2.3154800.1506830296.158864 $1469-159983587.1588641469$.

\section{Ethics approval and consent to participate}

Not applicable.

\section{Patient consent for publication}

Not applicable.

\section{Availability of data and material}

Data can be downloaded from UCSC Xena (https://xena.ucsc.edu/) and GlioVis (http://gliovis.bioinfo.cnio.es)

\section{Statements and Declarations}

The authors declare that they have no competing interests.

\section{Funding}

The present study was supported by The National Natural Science Foundation of China (grant nos. 81471279 and 81171138) and The Research Start-Up Fund of Wuxi School of Medicine, Jiangnan University (grant no. 1286010242190060). 


\section{Acknowledgements}

The authors thank UCSC Xena and GlioVis for the availability of the data.

\section{References}

1. Lapointe S, Perry A, Butowski NA. Primary brain tumours in adults. Lancet (London, England). 2018;392(10145):432-46.

2. Wang H, Liu G, Li T, Wang N, Wu J, Zhi H. MiR-330-3p functions as a tumor suppressor that regulates glioma cell proliferation and migration by targeting CELF1. Archives of medical science : AMS. 2020;16(5):1166-75.

3. Brat DJ, Verhaak RG, Aldape KD, Yung WK, Salama SR, Cooper LA, et al. Comprehensive, Integrative Genomic Analysis of Diffuse Lower-Grade Gliomas. The New England journal of medicine. 2015;372(26):2481-98.

4. Gittleman H, Sloan AE, Barnholtz-Sloan JS. An independently validated survival nomogram for lower-grade glioma. Neuro-oncology. 2020;22(5):665-74.

5. Kiran M, Chatrath A, Tang X, Keenan DM, Dutta A. A Prognostic Signature for Lower Grade Gliomas Based on Expression of Long Non-Coding RNAs. Molecular Neurobiology. 2018;56(7):4786-98.

6. Peng Z, Liu C, Wu M. New insights into long noncoding RNAs and their roles in glioma. Molecular Cancer. 2018;17(1).

7. Ulasov I, Fares J, Timashev P, Lesniak MS. Editing Cytoprotective Autophagy in Glioma: An Unfulfilled Potential for Therapy. Trends in Molecular Medicine. 2020;26(3):252-62.

8. Emdad L, Bhoopathi P, Talukdar S, Pradhan AK, Sarkar D, Wang XY, et al. Recent insights into apoptosis and toxic autophagy: The roles of MDA-7/IL-24, a multidimensional anti-cancer therapeutic. Seminars in cancer biology. 2020;66:140-54.

9. Lin JZ, Lin N. A risk signature of three autophagy-related genes for predicting lower grade glioma survival is associated with tumor immune microenvironment. Genomics. 2021;113(1 Pt 2):767-77.

10. Mizushima N. Autophagy: process and function. Genes \& development. 2007;21(22):2861-73.

11. Mizushima N, Yoshimori T, Ohsumi Y. The role of Atg proteins in autophagosome formation. Annual review of cell and developmental biology. 2011;27:107-32.

12. Mizushima N, Levine B, Cuervo AM, Klionsky DJ. Autophagy fights disease through cellular self-digestion. Nature. 2008;451(7182):1069-75.

13. Ma B, Gao Z, Lou J, Zhang H, Yuan Z, Wu Q, et al. Long non-coding RNA MEG3 contributes to cisplatin-induced apoptosis via inhibition of autophagy in human glioma cells. Mol Med Rep. 2017;16(3):2946-52.

14. Ulitsky I, Bartel DP. lincRNAs: genomics, evolution, and mechanisms. Cell. 2013;154(1):26-46.

15. Lin JZ, Lin N, Zhao WJ. Identification and validation of a six-lncRNA prognostic signature with its ceRNA networks and candidate drugs in lower-grade gliomas. Genomics. 2020;112(5):2990-3002.

16. Zhang J, Wang P, Wan L, Xu S, Pang D. The emergence of noncoding RNAs as Heracles in autophagy. Autophagy. 2017;13(6):1004-24. 
17. Ebadi N, Ghafouri-Fard S, Taheri M, Arsang-Jang S, Parsa SA, Omrani MD. Dysregulation of autophagy-related IncRNAs in peripheral blood of coronary artery disease patients. Eur J Pharmacol. 2020;867:172852.

18. Khorkova O, Hsiao J, Wahlestedt C. Basic biology and therapeutic implications of lncRNA. Advanced Drug Delivery Reviews. 2015;87:15-24.

19. Chen C-L, Tseng Y-W, Wu J-C, Chen G-Y, Lin K-C, Hwang S-M, et al. Suppression of hepatocellular carcinoma by baculovirus-mediated expression of long non-coding RNA PTENP1 and MicroRNA regulation. Biomaterials. 2015;44:71-81.

20. Zhang Y, Li X, Zhou D, Zhi H, Wang P, Gao Y, et al. Inferences of individual drug responses across diverse cancer types using a novel competing endogenous RNA network. Molecular oncology. 2018;12(9):1429-46.

21. Gittleman H, Lim D, Kattan MW, Chakravarti A, Gilbert MR, Lassman AB, et al. An independently validated nomogram for individualized estimation of survival among patients with newly diagnosed glioblastoma: NRG Oncology RTOG 0525 and 0825. Neuro-oncology. 2017;19(5):669-77.

22. Goldman M, Craft B, Hastie M, Repečka K, McDade F, Kamath A, et al. The UCSC Xena platform for public and private cancer genomics data visualization and interpretation. bioRxiv. 2019.

23. Bowman RL, Wang Q, Carro A, Verhaak RG, Squatrito M. GlioVis data portal for visualization and analysis of brain tumor expression datasets. Neuro-oncology. 2017;19(1):139-41.

24. Cunningham F, Achuthan P, Akanni W, Allen J, Amode M R, Armean IM, et al. Ensembl 2019. Nucleic acids research. 2018;47(D1):D745-D51.

25. Wright MW. A short guide to long non-coding RNA gene nomenclature. Human genomics. 2014;8:7.

26. Ritchie ME, Phipson B, Wu D, Hu Y, Law CW, Shi W, et al. limma powers differential expression analyses for RNA-sequencing and microarray studies. Nucleic Acids Research. 2015;43(7):e47-e.

27. Wang NN, Dong J, Zhang L, Ouyang D, Cheng Y, Chen AF, et al. HAMdb: a database of human autophagy modulators with specific pathway and disease information. Journal of cheminformatics. 2018;10(1):34.

28. Kuhn M. Building predictive models in $\mathrm{R}$ using the caret package. Journal of statistical software. 2008;28(5):1-26.

29. Pignatti F, van den Bent M, Curran D, Debruyne C, Sylvester R, Therasse P, et al. Prognostic factors for survival in adult patients with cerebral low-grade glioma. J Clin Oncol. 2002;20(8):2076-84.

30. Yang W, Warrington NM, Taylor SJ, Whitmire P, Carrasco E, Singleton KW, et al. Sex differences in GBM revealed by analysis of patient imaging, transcriptome, and survival data. Sci Transl Med. 2019;11(473).

31. Leu S, von Felten S, Frank S, Vassella E, Vajtai I, Taylor E, et al. IDH/MGMT-driven molecular classification of low-grade glioma is a strong predictor for long-term survival. Neuro-oncology. 2013;15(4):469-79.

32. Ostrom QT, Gittleman H, Truitt G, Boscia A, Kruchko C, Barnholtz-Sloan JS. CBTRUS Statistical Report: Primary Brain and Other Central Nervous System Tumors Diagnosed in the United States in 2011-2015. Neuro-oncology. 2018;20(suppl_4).

33. Stupp R, Brada M, van den Bent MJ, Tonn JC, Pentheroudakis G. High-grade glioma: ESMO Clinical Practice Guidelines for diagnosis, treatment and follow-up. Ann Oncol. 2014;25 Suppl 3:iii93-ii101.

34. Ding Y, Wang X, Pan J, Ji M, Luo Z, Zhao P, et al. Aberrant expression of long non-coding RNAs (lncRNAs) is involved in brain glioma development. Archives of medical science : AMS. 2020;16(1):177-88.

35. Blackshaw S, Harpavat S, Trimarchi J, Cai L, Huang H, Kuo WP, et al. Genomic analysis of mouse retinal development. PLoS Biol. 2004;2(9):E247.

36. Mercer TR, Qureshi IA, Gokhan S, Dinger ME, Li G, Mattick JS, et al. Long noncoding RNAs in neuronal-glial fate specification and oligodendrocyte lineage maturation. BMC Neurosci. 2010;11:14. 
37. Tian C, Deng Y, Jin Y, Shi S, Bi H. Long non-coding RNA RNCR3 promotes prostate cancer progression through targeting miR-185-5p. Am J Transl Res. 2018;10(5):1562-70.

38. Zhu B, Zhang S, Meng N, Zhang H, Yuan S, Zhang J. Long non-coding RNA RNCR3 promotes glioma progression involving the Akt/GSK-3 $\beta$ pathway. Oncol Lett. 2019;18(6):6315-22.

39. Xu G, Wang H, Yuan D, Yao J, Meng L, Li K, et al. RUNX1-activated upregulation of lncRNA RNCR3 promotes cell proliferation, invasion, and suppresses apoptosis in colorectal cancer via miR-1301-3p/AKT1 axis in vitro and in vivo. Clin Transl Oncol. 2020.

40. Zhang L, Cao Y, Wei M, Jiang X, Jia D. Long noncoding RNA-RNCR3 overexpression deleteriously affects the growth of glioblastoma cells through miR-185-5p/Krüppel-like factor 16 axis. Journal of Cellular Biochemistry. 2018;119(11):9081-9.

41. Fu Q, Li S, Zhou Q, Yalikun K, Yisireyili D, Xia M. Low LINC00599 expression is a poor prognostic factor in glioma. Bioscience Reports. 2019;39(4).

42. $\mathrm{Ku}$ BM, Lee YK, Ryu J, Jeong JY, Choi J, Eun KM, et al. CHI3L1 (YKL-40) is expressed in human gliomas and regulates the invasion, growth and survival of glioma cells. Int J Cancer. 2011;128(6):1316-26.

43. Gorlia T, Wu W, Wang M, Baumert BG, Mehta M, Buckner JC, et al. New validated prognostic models and prognostic calculators in patients with low-grade gliomas diagnosed by central pathology review: a pooled analysis of EORTC/RTOG/NCCTG phase III clinical trials. Neuro-oncology. 2013;15(11):1568-79.

44. Wang Y, Xin S, Zhang K, Shi R, Bao X. Low GAS5 Levels as a Predictor of Poor Survival in Patients with Lower-Grade Gliomas. J Oncol. 2019;2019:1785042.

45. Ostrom QT, Rubin JB, Lathia JD, Berens ME, Barnholtz-Sloan JS. Females have the survival advantage in glioblastoma. Neuro-oncology. 2018;20(4):576-7.

46. Eckel-Passow JE, Lachance DH, Molinaro AM, Walsh KM, Decker PA, Sicotte H, et al. Glioma Groups Based on 1p/19q, IDH, and TERT Promoter Mutations in Tumors. N Engl J Med. 2015;372(26):2499-508.

47. Goodenberger ML, Jenkins RB. Genetics of adult glioma. Cancer Genet. 2012;205(12):613-21. 


\section{Legend}

Fig. 1 Flow chart of study design.

Fig. 2 Screening of lncRNAs used for constructing the risk signature for lower-grade gliomas (LGG). (a) Principal components analysis of lncRNAs between LGG and normal brain tissues. (b) Volcano plot showed the distribution of differentially expressed lncRNAs (DElncRNAs) between LGG and normal brain tissues. (c) Heatmap exhibited the expression levels of the DElncRNAs. (d) Boxplot showed the expressions of DElncRNAs. The green and red boxes showed the DElncRNA expression in LGG and normal brain tissue, respectively. (e) The networks constructed by autophagy-related DElncRNAs (blue rectangle) and autophagy-related genes (yellow ellipse). Positive and negative Pearson coefficients were illustrated by red line and green line, respectively. The width of the line was proportional to the correlation

Fig. 3 Identification of the autophagy-related differentially expressed lncRNAs (ATG DElncRNA). (a) Log (Lambda) value of the 20 ATG DElncRNAs in least absolute shrinkage and selection operator (LASSO) model. (b) The most appropriate log (Lambda) value in the LASSO model. (c) Multivariate Cox regression analysis was performed and six ATG DElncRNAs (AC021739.2, AL118505.1, LINC00599, AL590666.2, LINC02609, and AL354892.2) were identified to for further construction of the risk signature

Fig. 4 Characteristics of the autophagy-related differentially expressed lncRNAs (ATG DElncRNA) risk signature in the training cohort. (a) lncRNA expression profiles, risk score 
distributions and patient survival in the training cohort. (b) Survival curves for high-risk and low-risk groups classified by the risk signature in the training cohort. (c-e) Receiver operating characteristic (ROC) curves for the 1-(c), 3- (d), and 5- (e) year survival according to the ATG DElncRNA risk signature in the training cohort

Fig. 5 Efficacy of the autophagy-related differentially expressed lncRNAs (ATG DElncRNA) risk signature in the validation cohort. (a) LncRNA expression profiles, risk score distributions and patient survival in the validation cohort. (b) Survival curves for high-risk and low-risk groups classified by the risk signature in the validation cohort. (c-e) Receiver operating characteristic (ROC) curves for the 1- (c), 3- (d), and 5- (e) year survival according to the ATG DElncRNA risk signature in the validation cohort

Fig. 6 Assessment of the survival prognostic value of the risk signature, as well as clinical (grade, age, and gender) and molecular variables (IDH status and MGMT status) in LGG patients. (a-e) Kaplan-Meier survival curves showed the survival probabilities for LGG patients by grade (a), IDH status (b), MGMT status (c), age (d), and gender (e). (f-g) Univariate (f) and multivariate (g) Cox regression analyses evaluated the contribution of each variable to LGG survival. (h) Nomogram was developed by integrating the risk signature with age, grade, IDH status and MGMT status for predicting LGG survival. (i-k) ROC curves to evaluate the accuracy of each variable for predicting 1- (i), 3- (j), and 5- (k) year survival were shown with areas under curves (AUCs) 
Fig. 7 Evaluation of the performance of the nomogram for survival prediction. (a) ROC curves showed the accuracy of the nomogram for predicting 1-, 3-, and 5- year survival in the training cohort. (b-d) Calibration curves showed the predicted values and the observed values of patient survival at 1- (b), 3- (c) and 5-(d) year in the training cohort. (e) ROC curves showed the accuracy of the nomogram for predicting 1-, 3-, and 5- year survival in the validation cohort. (f-h) Calibration curves showed the predicted values and the observed values of patient survival at 1-(f), 3- (g) and 5-(h) year survival in the validation cohort

Fig. S1 The relationships between the six autophagy-related differentially expressed lncRNAs and their co-expressed genes shown by Sankey diagram. The six autophagy-related lncRNAs were divided into protective and risk lncRNAs according to the hazard ratios

Fig. S2 Functional roles of the risk signature by the gene set enrichment analysis (GSEA). GO analysis showed gene sets related to autophagosome membrane (a), cell matrix adhesion (b) and regulation of cell junction assembly (c) were enriched in LGG patients with the high-risk score, while a gene set related to ribosome assembly (d) was enriched in LGG patients with a low risk score. KEGG showed that gene sets were enriched in the pathway of regulation of autophagy (e), MAPK signaling pathway (f), and ECM receptor interaction (g) in LGG patients with high- risk score, while a gene set related to ribosome (h) was enriched in LGG patients with a low risk score 
Table 1. Clinicopathological characteristics of samples in the training cohort and the validation cohort.

\begin{tabular}{ccc}
\hline \multicolumn{2}{c}{$\begin{array}{c}\text { Clinicopathological } \\
\text { characteristics }\end{array}$} & Number of samples \\
\cline { 2 - 3 } Trainning cohort(n=252) & Validation cohort(n=252) \\
\hline WHO Grade & 109 & 116 \\
Grade II & 121 & 119 \\
Grade III & 22 & 17 \\
Unknown & & \\
Age $\quad 44.01$ & 42.52 \\
Average value & $14-87$ & $18-75$ \\
Range & 32 & 25 \\
Unknown & & 109 \\
Gender & 87 & 118 \\
Male & 133 & 25 \\
Female & 32 & \\
Unknown & &
\end{tabular}


Table S1. $P$ value of the autophagy-related DEIncRNAs with Kaplan-Meier analysis and Univariate Cox proportional hazards regression

\begin{tabular}{ccc}
\hline gene & Kmpvalue & $\begin{array}{c}\text { Unicox } \\
\text { pvalue }\end{array}$ \\
\hline AC021739.2 & 0.000341 & $3.08 \mathrm{E}-05$ \\
AC053503.1 & $7.32 \mathrm{E}-05$ & $3.07 \mathrm{E}-06$ \\
AC093010.3 & 0.000113 & 0.001098 \\
AL118505.1 & 0.000404 & $3.87 \mathrm{E}-09$ \\
AL121827.2 & 0.019342 & $3.05 \mathrm{E}-05$ \\
AL354892.2 & $9.71 \mathrm{E}-05$ & $7.67 \mathrm{E}-08$ \\
AL355916.2 & 0.006057 & 0.025537 \\
AL590666.2 & 0.003906 & 0.018444 \\
LINC00599 & 0.00955 & 0.003334 \\
LINC02283 & 0.002057 & $7.52 \mathrm{E}-08$ \\
LINC02609 & 0.009672 & 0.009522 \\
NEAT1 & 0.023499 & $7.96 \mathrm{E}-05$ \\
\hline
\end{tabular}


Table S2. TOP 100 enriched GO functions in high risk group

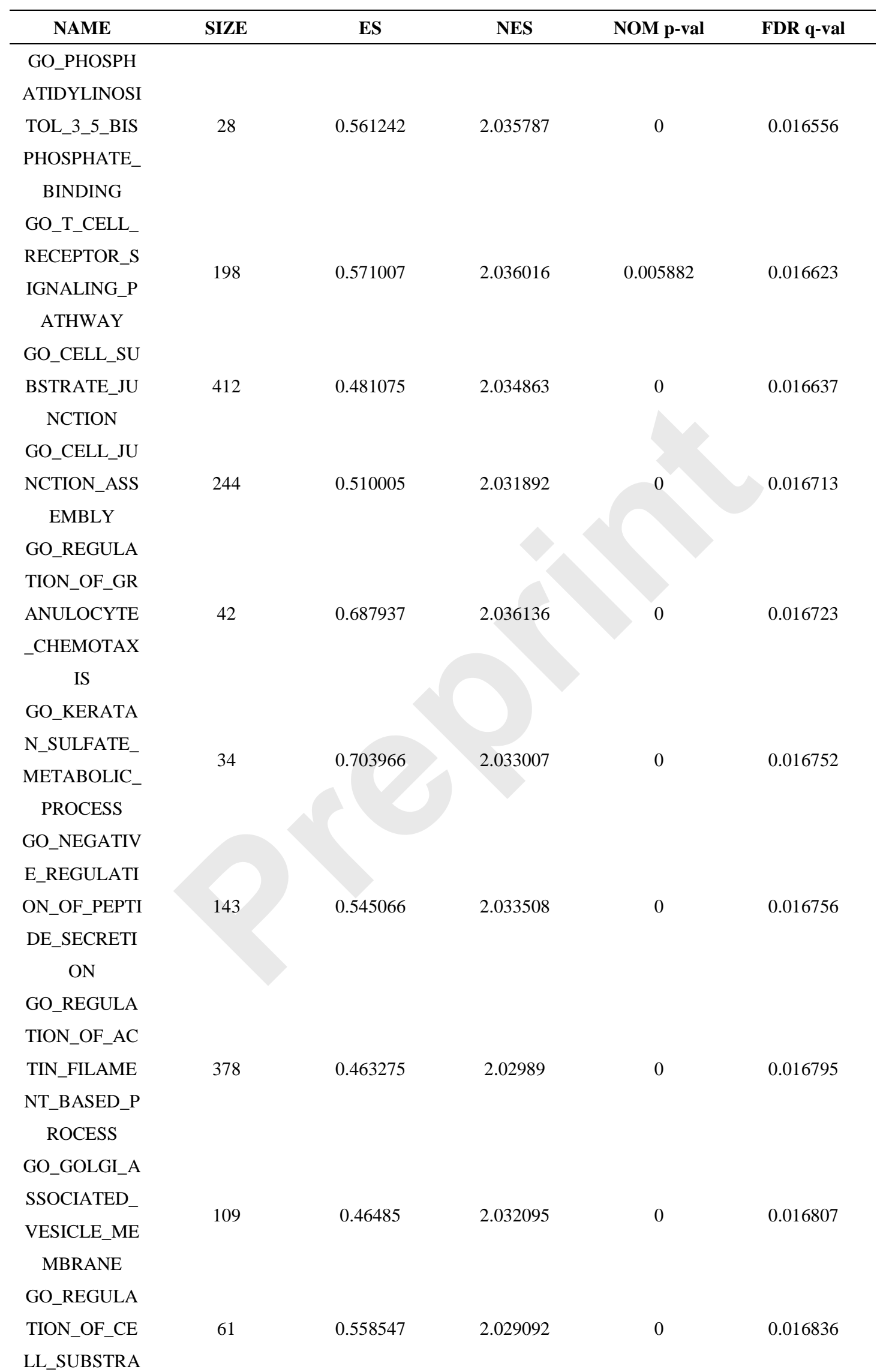




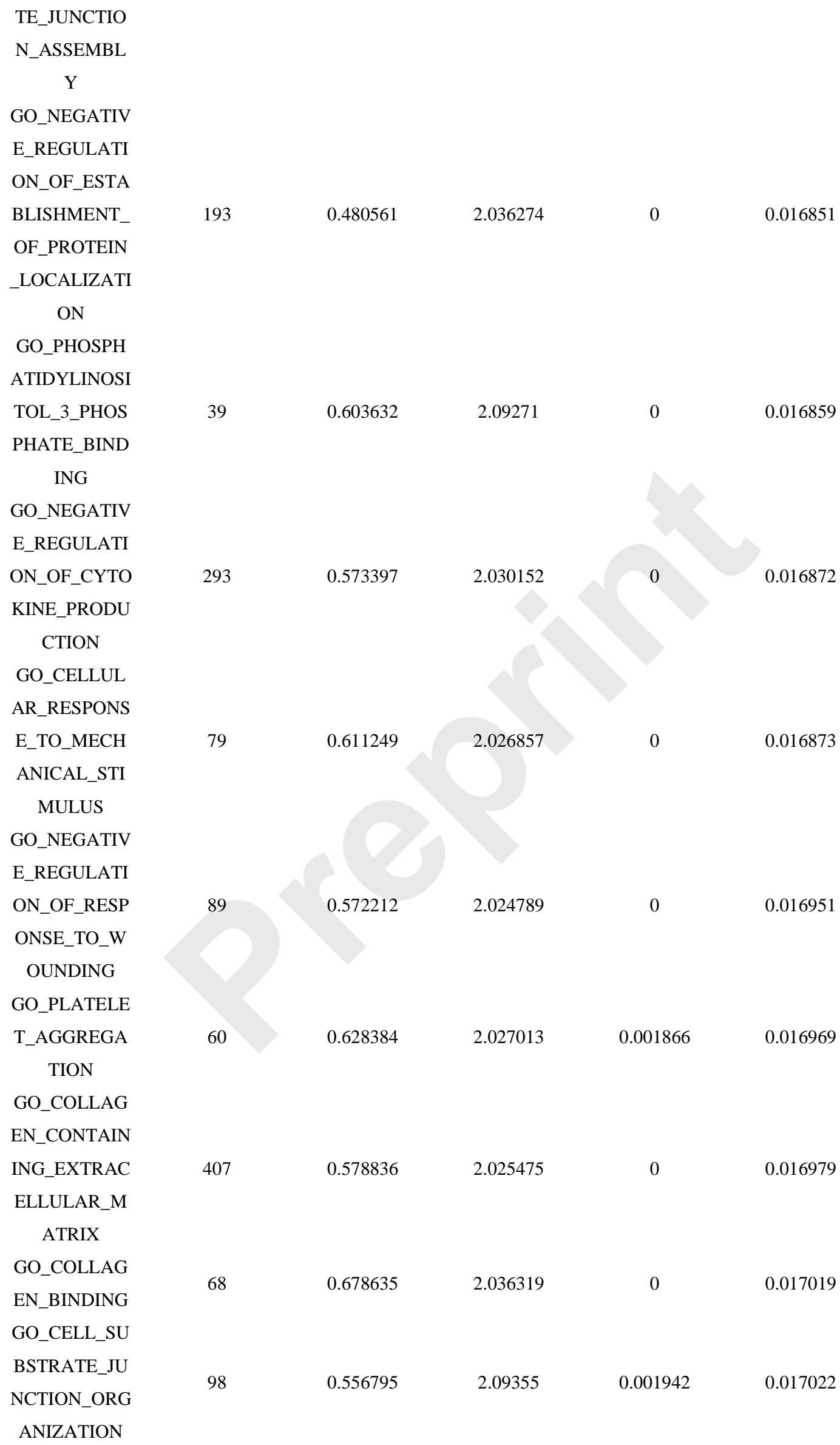




\begin{tabular}{|c|c|c|c|c|c|}
\hline \multicolumn{6}{|l|}{ GO_RESPONS } \\
\hline $\begin{array}{l}\text { E_TO_MECH } \\
\text { ANICAL_STI }\end{array}$ & \multirow[t]{2}{*}{211} & \multirow[t]{2}{*}{0.51361} & \multirow[t]{2}{*}{2.037198} & \multirow[t]{2}{*}{0} & \multirow[t]{2}{*}{0.017033} \\
\hline MULUS & & & & & \\
\hline \multicolumn{6}{|l|}{ GO_CELLUL } \\
\hline \multicolumn{6}{|l|}{ AR_RESPONS } \\
\hline E_TO_EXTRA & 261 & 0.446498 & 2.027829 & 0 & 0.017058 \\
\hline \multicolumn{6}{|l|}{ CELLULAR_S } \\
\hline \multicolumn{6}{|l|}{ TIMULUS } \\
\hline GO_EPIBOLY & 32 & 0.669239 & 2.027167 & 0 & 0.01711 \\
\hline \multicolumn{6}{|l|}{ GO_CELLUL } \\
\hline $\begin{array}{l}\text { AR_GLUCAN } \\
\text { _METABOLIC }\end{array}$ & \multirow[t]{2}{*}{74} & \multirow[t]{2}{*}{0.551488} & \multirow[t]{2}{*}{2.094342} & \multirow[t]{2}{*}{0} & \multirow[t]{2}{*}{0.017129} \\
\hline _PROCESS & & & & & \\
\hline \multicolumn{6}{|l|}{ GO_GROWTH } \\
\hline _FACTOR_BI & 137 & 0.602065 & 2.037377 & 0 & 0.017166 \\
\hline \multicolumn{6}{|l|}{ NDING } \\
\hline \multicolumn{6}{|l|}{ GO_ACTIN_FI } \\
\hline LAMENT_BU & 70 & 0.572732 & 1.964708 & 0 & 0.017168 \\
\hline \multicolumn{6}{|l|}{ NDLE } \\
\hline \multicolumn{6}{|l|}{ GO_PHAGOC } \\
\hline YTIC_VESICL & 131 & 0.604129 & 2.099622 & 0 & 0.017195 \\
\hline \multicolumn{6}{|l|}{$\mathrm{E}$} \\
\hline \multicolumn{6}{|l|}{ GO_POSITIVE } \\
\hline \multicolumn{6}{|l|}{ _REGULATIO } \\
\hline \multicolumn{6}{|l|}{ N_OF_DNA_B } \\
\hline INDING_TRA & 258 & 0.478985 & 1.964856 & 0.002012 & 0.017211 \\
\hline \multicolumn{6}{|l|}{ NSCRIPTION_ } \\
\hline FACTOR_ACT & & & & & \\
\hline IVITY & & & & & \\
\hline GO_REGULA & & & & & \\
\hline TION_OF_HE & 444 & 0.510226 & 1.967051 & 0.002004 & 0.017215 \\
\hline MOPOIESIS & & & & & \\
\hline GO_RESPONS & 49 & 0.5529 & 1968744 & 0 & 0017233 \\
\hline E_TO_COLD & & & & & \\
\hline GO_ORGANE & & & & & \\
\hline LLE_DISASSE & 99 & 0.393933 & 2.000475 & 0 & 0.017242 \\
\hline MBLY & & & & & \\
\hline GO_POSITIVE & & & & & \\
\hline _REGULATIO & & & & & \\
\hline N_OF_EPITHE & 163 & 0.501388 & 1.964088 & 0 & 0.017246 \\
\hline LIAL_CELL_ & & & & & \\
\hline MIGRATION & & & & & \\
\hline
\end{tabular}


GO_CELL_MI

GRATION_IN

VOLVED_IN_

SPROUTING

87

0.569169

1.968201

0.003899

0.017252

ANGIOGENES

IS

GO_ACTIN_C YTOSKELET

ON_REORGA

0.527181

1.963861

0

0.017254

NIZATION

GO_REGULA

TION_OF_GL

YCOGEN_ME

0.585097

1.96719

0

0.017257

TABOLIC_PR

OCESS

GO_REGULA

TION_OF_VA

SOCONSTRIC

58

$0.658629 \quad 2.038044$

0

0.017258

TION

GO_ORGANE

LLE_SUBCO

0.402996

1.96774

0

0.017261

MPARTMENT

GO_GROWTH

_FACTOR_RE

CEPTOR_BIN

0.523218

1.964897

0

0.017279

DING

GO_CELLUL

AR_TRANSITI

ON_METAL_I

110

0.452484

1.968806

0

0.017296

ON_HOMEOS

TASIS

GO_FAT_SOL

UBLE_VITAM

IN_METABOL

0.649742

1.96726

0

0.017303

IC_PROCESS

GO_POSITIVE

_REGULATIO

N_OF_MYEL

OID_CELL_DI

92

0.627052

2.066803

0

0.017307

FFERENTIATI

ON

GO_NEGATIV

E_REGULATI

31

0.580518

1.973933

0.001876

0.017308 
AL_TRANSD

UCTION_BY_ P53_CLASS_

MEDIATOR

GO_NEGATIV

E_REGULATI

ON_OF_CYST

EINE_TYPE_E

NDOPEPTIDA

SE_ACTIVITY

GO_SYNCYTI

UM_FORMAT

ION

GO_REGULA

TION_OF_ER

BB_SIGNALI

NG_PATHWA

$$
\mathrm{Y}
$$

GO_REGULA

TION_OF_BIC

ELLULAR_TI GHT_JUNCTI

ON_ASSEMB

LY

GO_PLACENT

A_DEVELOP

MENT

GO_HEPARIN BINDING

GO_INTRINSI

C_COMPONE

NT_OF_ENDO

PLASMIC_RE

TICULUM_M

EMBRANE

GO_RECEPTO

R_CATABOLI

C_PROCESS

GO_REGULA TION_OF_SY

STEMIC_ART

ERIAL_BLOO

D_PRESSURE _MEDIATED_
0.555556

2.000807

0

0.017312

59

0.585111

1.978205

0

0.017318

89

0.497655

1.97653

0

0.01732

22

0.750304

1.969197

0

0.017321

0.518545

2.038586

0

0.017324

0.549429

1.964969

0

0.017331

157

0.443332

1.970077

0.001992

0.017334

36

0.543197

1.963301

0.002101

0.017334

49

0.621355

1.970477

0

0.017336 
BY_A_CHEMI

CAL_SIGNAL

GO_TYPE_2_I

MMUNE_RES

0.729836

1.974052

0

0.017349

PONSE

GO_CELLUL

AR_RESPONS

E_TO_OSMOT

40

0.567791

1.970663

0

0.01735

IC_STRESS

GO_PHOSPH

ATIDYLINOSI

TOL_METAB

176

0.462833

1.982401

0

0.017354

OLIC_PROCE

SS

GO_REGULA

TION_OF_PR

ODUCTION_O

F_MOLECUL

AR_MEDIAT

140

0.610148

1.965173

0.004008

0.017365

OR_OF_IMM

UNE_RESPON

SE

GO_POSITIVE

REGULATIO

N_OF_VACU

0.672656

1.98318

0

0.017366

OLE_ORGANI

ZATION

GO_RESPONS

E_TO_VIRUS

0.549361

1.978416

0.003868

0.017369

GO_LEUKOC

YTE_CHEMO

219

0.613631

1.974839

0.001927

0.017371

TAXIS

GO_RESPONS

E_TO_MOLEC

ULE_OF_BAC

0.557128

1.980678

0.001927

0.017372

TERIAL_ORI

GIN

GO_POSITIVE

_REGULATIO

N_OF_VASCU

216

0.586325

2.097044

0

0.017375

LATURE_DE

VELOPMENT 


\begin{tabular}{|c|c|c|c|c|c|}
\hline \multicolumn{6}{|l|}{ GO_RESPONS } \\
\hline E_TO_PEPTID & 433 & 0.408034 & 1.969336 & 0 & 0.017377 \\
\hline \multicolumn{6}{|l|}{ E_HORMONE } \\
\hline \multicolumn{6}{|l|}{ GO_PLATELE } \\
\hline \multirow{2}{*}{\multicolumn{6}{|c|}{$\begin{array}{l}\text { T_ALPHA_GR } \\
\text { ANULE_LUM }\end{array}$}} \\
\hline & & & & & \\
\hline \multicolumn{6}{|l|}{$\mathrm{EN}$} \\
\hline \multicolumn{6}{|l|}{ GO_REGULA } \\
\hline \multicolumn{6}{|l|}{ TION_OF_TU } \\
\hline \multicolumn{6}{|l|}{ MOR_NECRO } \\
\hline SIS_FACTOR_ & 57 & 0.571639 & 2.001105 & 0.003929 & 0.017379 \\
\hline \multicolumn{6}{|l|}{ MEDIATED_S } \\
\hline \multicolumn{6}{|l|}{ IGNALING_P } \\
\hline \multicolumn{6}{|l|}{ ATHWAY } \\
\hline \multicolumn{6}{|l|}{ GO_CELL_AD } \\
\hline \multirow{3}{*}{\multicolumn{6}{|c|}{$\begin{array}{c}\text { HESION_MED } \\
\text { IATOR_ACTI } \\
\text { VITY }\end{array}$}} \\
\hline & & & & & \\
\hline & & & & & \\
\hline \multicolumn{6}{|l|}{ GO_REGULA } \\
\hline \multicolumn{6}{|l|}{ TION_OF_RE } \\
\hline SPONSE_TO_ & 183 & 0.595775 & 2.094889 & 0 & 0.017387 \\
\hline \multicolumn{6}{|l|}{ CYTOKINE_S } \\
\hline \multicolumn{6}{|l|}{ TIMULUS } \\
\hline \multicolumn{6}{|l|}{ GO_RHO_PR } \\
\hline \multicolumn{6}{|l|}{ OTEIN_SIGN } \\
\hline \multicolumn{6}{|l|}{ AL_TRANSD } \\
\hline \multicolumn{6}{|l|}{ UCTION } \\
\hline \multicolumn{6}{|l|}{ GO_POST_TR } \\
\hline \multicolumn{6}{|l|}{ ANSLATIONA } \\
\hline L_PROTEIN_ & 363 & 0.38525 & 1.982594 & 0 & 0.01739 \\
\hline \multicolumn{6}{|l|}{ MODIFICATI } \\
\hline ON & & & & & \\
\hline GO_RAS_PRO & & & & & \\
\hline TEIN_SIGNAL & 446 & 0.433282 & 1.977478 & 0001961 & 0.01739 \\
\hline _TRANSDUC & & & & & \\
\hline TION & & & & & \\
\hline GO_POSITIVE & & & & & \\
\hline _REGULATIO & & & & & \\
\hline N_OF_MAP_K & 253 & 0.462041 & 1.981245 & 0 & 0.017399 \\
\hline INASE_ACTI & & & & & \\
\hline VITY & & & & & \\
\hline GO_EXTRAC & & & & & \\
\hline ELLULAR_ST & 370 & 0.589636 & 2.021354 & 0 & 0.017403 \\
\hline RUCTURE_O & & & & & \\
\hline
\end{tabular}


RGANIZATIO

$\mathrm{N}$

GO_REGULA

TION_OF_SY

STEMIC_ART

92

0.562044

1.975784

0

0.017405

ERIAL_BLOO

D_PRESSURE

GO_POSITIVE

_REGULATIO

N_OF_COLD_

INDUCED_TH

97

$0.520958 \quad 1.986694$

0

0.01741

ERMOGENES

$\mathrm{S}$

GO_EPITHELI

AL_CELL_AP

OPTOTIC_PR

108

0.547505

1.969491

0.003854

0.017412

OCESS

GO_POSITIVE

_REGULATIO

N_OF_SMOO

TH_MUSCLE_

44

0.646477

1.979135

0

0.017415

CELL_MIGRA

TION

GO_REGULA

TION_OF_EX

TRINSIC_APO

PTOTIC_SIGN

ALING_PATH

0.637008

1.974223

0

0.017416

WAY_VIA_D

EATH_DOMA

IN_RECEPTO

RS

GO_RESPONS

E_TO_STEROI

0.438781

1.988199

0

0.017422

D_HORMONE

GO_PEPTIDA

SE_REGULAT

OR_ACTIVIT

221

0.52582

1.965861

0

0.017425

$\mathrm{Y}$

GO_RUFFLE

170

0.487888

1.9749

0.003891

0.017426

GO_MICROVI

LLUS

84

0.536131

1.986188

0

0.017428

GO_INTRACE

LLULAR_REC

276

0.426416

1.972906

0

0.017429 


\begin{tabular}{|c|c|c|c|c|c|}
\hline \multicolumn{6}{|l|}{ EPTOR_SIGN } \\
\hline \multicolumn{6}{|l|}{ ALING_PATH } \\
\hline \multicolumn{6}{|l|}{ WAY } \\
\hline \multicolumn{6}{|l|}{ GO_REGULA } \\
\hline $\begin{array}{l}\text { TION_OF_LIP } \\
\text { ID_METABOL }\end{array}$ & 410 & 0.422613 & 1.980725 & 0 & 0.01743 \\
\hline \multicolumn{6}{|l|}{ IC_PROCESS } \\
\hline \multicolumn{6}{|l|}{ GO_ENZYME } \\
\hline $\begin{array}{c}\text { _INHIBITOR_ } \\
\text { ACTIVITY }\end{array}$ & 372 & 0.441698 & 1.987476 & 0 & 0.01743 \\
\hline \multicolumn{6}{|l|}{ GO_ACUTE_I } \\
\hline $\begin{array}{l}\text { NFLAMMATO } \\
\text { RY_RESPONS }\end{array}$ & 107 & 0.642459 & 1.965262 & 0 & 0.017431 \\
\hline \multicolumn{6}{|l|}{$\mathrm{E}$} \\
\hline \multicolumn{6}{|l|}{ GO_INOSITO } \\
\hline $\begin{array}{l}\text { L_PHOSPHAT } \\
\text { E_MEDIATED } \\
\text { _SIGNALING }\end{array}$ & 56 & 0.555441 & 1.972326 & 0 & 0.017431 \\
\hline $\begin{array}{c}\text { GO_LIPID_DR } \\
\text { OPLET }\end{array}$ & 82 & 0.515753 & 2.065356 & 0 & 0.017434 \\
\hline \multicolumn{6}{|l|}{ GO_LIPID_TR } \\
\hline $\begin{array}{c}\text { ANSPORTER_ } \\
\text { ACTIVITY }\end{array}$ & \multirow[t]{2}{*}{122} & \multirow[t]{2}{*}{0.515524} & 1.979408 & 0 & 0.017435 \\
\hline \multicolumn{4}{|l|}{ GO_REGULA } & & \\
\hline TION_OF_T_C & & & & & \\
\hline $\begin{array}{l}\text { ELL_RECEPT } \\
\text { OR_SIGNALI }\end{array}$ & 39 & 0.704616 & 1.981707 & 0 & 0.017437 \\
\hline NG_PATHWA & & & & & \\
\hline $\mathrm{Y}$ & & & & & \\
\hline $\begin{array}{l}\text { GO_INTEGRI } \\
\text { N_BINDING }\end{array}$ & 135 & 0.617678 & 2.03874 & 0 & 0.017437 \\
\hline GO_AMINOG & & & & & \\
\hline $\begin{array}{l}\text { LYCAN_MET } \\
\text { ABOLIC_PRO }\end{array}$ & 168 & 0.535746 & 1.98328 & 0 & 0.017443 \\
\hline CESS & & & & & \\
\hline GO_REGULA & & & & & \\
\hline TION_OF_GL & & & & & \\
\hline UCAN_BIOSY & 28 & 0.576106 & 1.97848 & 0 & 0.017447 \\
\hline NTHETIC_PR & & & & & \\
\hline OCESS & & & & & \\
\hline GO_AZUROP & & & & & \\
\hline $\begin{array}{c}\text { HIL_GRANUL } \\
\text { E_LUMEN }\end{array}$ & 90 & 0.594462 & 1.975098 & 0.001957 & 0.017447 \\
\hline
\end{tabular}




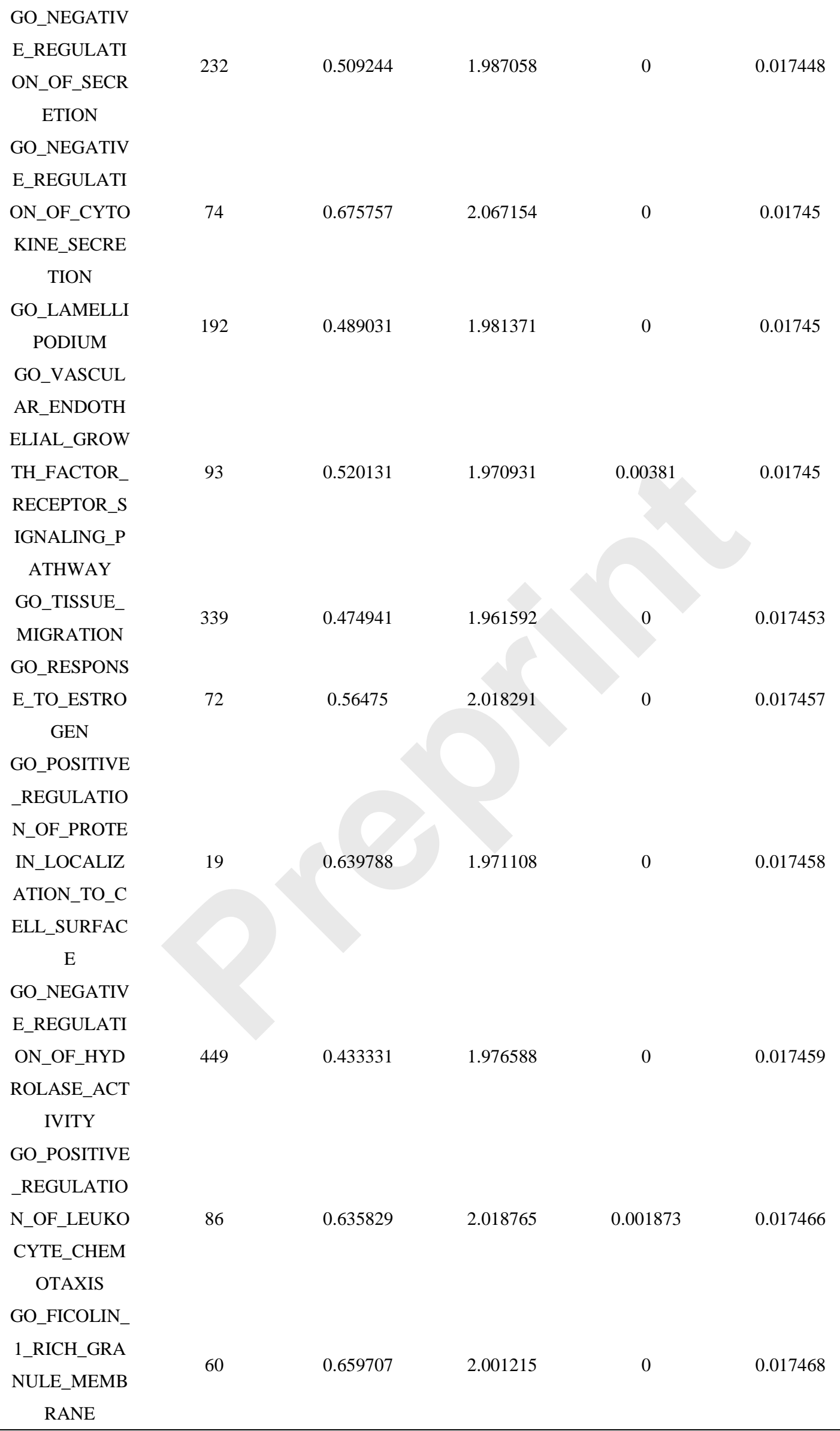


Table S3. Enriched GO functions in low risk group

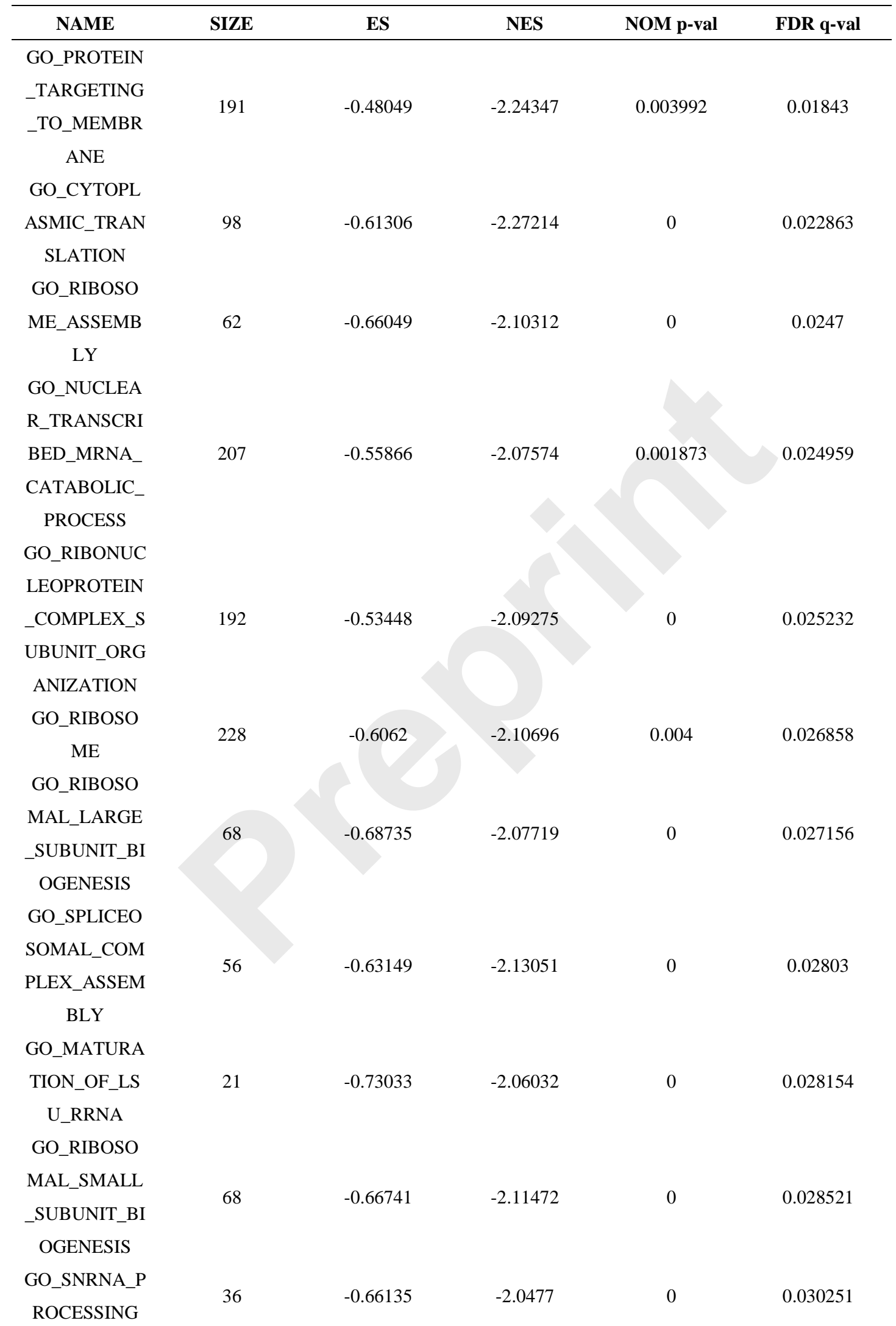


GO_TRANSL

ATIONAL IN

192

$-0.55057$

$-2.13742$

0.001905

0.032196

TIATION

GO_ESTABLI

SHMENT_OF_

PROTEIN_LO

CALIZATION

321

$-0.37144$

$-2.017$

0.002037

0.037769

_TO_MEMBR

ANE

GO_NUCLEA

R_TRANSCRI

BED_MRNA_

CATABOLIC

PROCESS_NO

120

$-0.68894$

$-2.0227$

0.001942

0.038108

NSENSE_ME

DIATED_DEC

AY

GO_RIBONUC

LEOPROTEIN

_COMPLEX_B

417

$-0.54035$

$-2.0088$

0

0.039489

IOGENESIS

GO_POLYSO

ME

73

$-0.60048$

$-2.13994$

0.001934

0.041744

GO_MRNA_S

PLICE_SITE_S

30

$-0.66613$

$-1.9933$

0

0.042847

ELECTION

GO_LARGE_R

IBOSOMAL_S

$-0.66087$

$-1.99741$

0.005941

0.043215

UBUNIT

GO_RIBOSO

MAL_SUBUNI

$-0.64563$

$-1.98322$

0.008114

0.043735

$\mathrm{T}$

GO_MATURA

TION_OF_SS

U_RRNA_FRO

M_TRICISTR

ONIC_RRNA_

35

$-0.66001$

$-1.9859$

0

0.044647

TRANSCRIPT

_SSU_RRNA_

5_8S_RRNA_L

SU_RRNA

GO_SNRNA_3

_END_PROCE

30

$-0.64969$

$-1.96689$

0.002

0.045122 
GO_SMALL_S

UBUNIT_PRO

CESSOME

GO_RIBOSO

MAL_LARGE

_SUBUNIT_A

0

0.045967

SSEMBLY

GO_RIBOSO

ME_BIOGENE

289

$-0.55207$

$-1.93556$

0.005837

0.049691

SIS

GO_NBAF_C OMPLEX

$-0.72875$

$-1.95412$

0

0.049698

GO_CYTOSO

LIC_RIBOSO

104

$-0.71368$

$-1.92759$

0.006048

0.049911

ME

GO_RIBOSO

MAL_SMALL

_SUBUNIT_A

19

$-0.71972$

$-1.93693$

0.001931

0.050372

SSEMBLY

GO_DNA_HE

LICASE_COM

15

$-0.70093$

$-1.92901$

0

0.050446

PLEX

GO_NUCLEA

R_EXOSOME

_RNASE_CO

16

$-0.76396$

$-1.93022$

0

0.051276

MPLEX

GO_MATURA

TION_OF_SS

$-0.62708$

$-1.91035$

0.001942

0.051491

U_RRNA

GO_INO80_T

YPE_COMPLE

$-0.62175$

$-1.9034$

0.003937

0.051517

$\mathrm{X}$

GO_SMALL_

RIBOSOMAL_

$-0.62197$

$-1.91461$

0.01004

0.051568

SUBUNIT

GO_CYTOSO

LIC_SMALL_

RIBOSOMAL_

44

$-0.72424$

$-1.90546$

0.004016

0.051658

SUBUNIT

GO_SNRNA_

METABOLIC

45

$-0.60853$

$-1.93777$

0.003937

0.051679

PROCESS

GO_PROTEIN

_LOCALIZATI

136

$-0.5312$

$-1.91682$

0.015748

0.0518 
ON_TO_END

OPLASMIC_R

ETICULUM

GO_RRNA_M

ETABOLIC_P

221

$-0.54191$

$-1.91131$

0.007752

0.052155

ROCESS

GO_REGULA

TION_OF_MR

NA_POLYAD

17

$-0.61744$

$-1.9185$

0

0.052181

ENYLATION

GO_ESCRT_C OMPLEX

26

$-0.50998$

$-1.92073$

0.007952

0.052369

GO_ESTABLI

SHMENT_OF_

PROTEIN_LO

CALIZATION

111

$-0.6477$

$-1.89939$

0.007905

0.052712

_TO_ENDOPL

ASMIC_RETI

CULUM

GO_PRERIBO

SOME

77

$-0.62277$

$-1.90574$

0.007813

0.052732

GO_TRANSL

ATIONAL_EL

$-0.46319$

$-1.93911$

0.033268

0.052746

ONGATION

GO_CYTOPL

ASMIC_TRAN

SLATIONAL_I

$-0.58886$

$-1.89717$

0.001883

0.052782

NITIATION

GO_NCRNA_

PROCESSING

$-0.52259$

$-1.89137$

0.009766

0.052823

GO_PROTEIN

_TARGETING

$-0.30207$

$-1.89203$

0.003968

0.0536

GO_RNA_SPL

ICING_VIA_T

RANSESTERI

343

$-0.45807$

$-1.93986$

0.009434

0.054147

FICATION_RE ACTIONS

GO_TRANSL ATION_INITI ATION_FACT 


\begin{tabular}{|c|c|c|c|c|c|}
\hline \multicolumn{6}{|l|}{ GO_POLYSO } \\
\hline MAL_RIBOSO & 32 & -0.7682 & -1.89204 & 0.00198 & 0.054785 \\
\hline \multicolumn{6}{|l|}{ ME } \\
\hline \multicolumn{6}{|l|}{ GO_U2_TYPE } \\
\hline $\begin{array}{l}\text { _SPLICEOSO } \\
\text { MAL_COMPL }\end{array}$ & \multirow[t]{2}{*}{93} & \multirow[t]{2}{*}{-0.53824} & \multirow[t]{2}{*}{-1.88524} & \multirow[t]{2}{*}{0.005906} & \multirow[t]{2}{*}{0.055112} \\
\hline EX & & & & & \\
\hline \multicolumn{6}{|l|}{ GO_HISTONE } \\
\hline _H3_ACETYL & 59 & -0.50965 & -1.88061 & 0.005803 & 0.055415 \\
\hline \multicolumn{6}{|l|}{ ATION } \\
\hline \multicolumn{6}{|l|}{ GO_STRUCT } \\
\hline $\begin{array}{l}\text { URAL_CONS } \\
\text { TITUENT_OF }\end{array}$ & \multirow[t]{2}{*}{162} & \multirow[t]{2}{*}{-0.67042} & \multirow[t]{2}{*}{-1.94065} & \multirow[t]{2}{*}{0.010246} & \multirow[t]{2}{*}{0.055611} \\
\hline _RIBOSOME & & & & & \\
\hline \multicolumn{6}{|l|}{ GO_TRANSL } \\
\hline $\begin{array}{l}\text { ATION_PREI } \\
\text { NITIATION_C }\end{array}$ & \multirow[t]{2}{*}{18} & \multirow[t]{2}{*}{-0.7125} & \multirow[t]{2}{*}{-1.8672} & \multirow[t]{2}{*}{0} & \multirow[t]{2}{*}{0.061622} \\
\hline OMPLEX & & & & & \\
\hline \multicolumn{6}{|l|}{ GO_VIRAL_G } \\
\hline ENE_EXPRES & 192 & -0.52075 & -1.86758 & 0.015267 & 0.062602 \\
\hline \multicolumn{6}{|l|}{ SION } \\
\hline \multicolumn{6}{|l|}{ GO_NUCLEA } \\
\hline \multicolumn{6}{|l|}{ R_TRANSCRI } \\
\hline BED_MRNA_ & & & & & \\
\hline CATABOLIC_ & 35 & -0.6123 & -1.85864 & 0.007797 & 0.064142 \\
\hline PROCESS_EX & & & & & \\
\hline ONUCLEOLY & & & & & \\
\hline TIC & & & & & \\
\hline GO_90S_PRE & 32 & -0.61128 & -1.85978 & 0.007767 & 0.064484 \\
\hline RIBOSOME & & & & & \\
\hline $\begin{array}{c}\text { GO_VIRION_ } \\
\text { ASSEMBLY }\end{array}$ & 39 & -0.43279 & -1.85456 & 0.00789 & 0.065451 \\
\hline GO_RESPIRA & & & & & \\
\hline TORY_CHAIN & & & & & \\
\hline _COMPLEX_I & 24 & -0.57034 & -1.85277 & 0.019763 & 0.065491 \\
\hline V_ASSEMBL & & & & & \\
\hline $\mathrm{Y}$ & & & & & \\
\hline GO_TRANSL & & & & & \\
\hline ATION_ELON & & & & & \\
\hline GATION_FAC & 20 & -0.57385 & -1.85997 & 0.012 & 0.065563 \\
\hline TOR_ACTIVI & & & & & \\
\hline TY & & & & & \\
\hline $\begin{array}{l}\text { GO_SMALL_ } \\
\text { NUCLEAR_RI }\end{array}$ & 66 & -0.53248 & -1.85095 & 0.007874 & 0.065586 \\
\hline
\end{tabular}




\begin{tabular}{|c|c|c|c|c|c|}
\hline \multicolumn{6}{|l|}{ BONUCLEOP } \\
\hline \multicolumn{6}{|l|}{ ROTEIN_COM } \\
\hline \multicolumn{6}{|l|}{ PLEX } \\
\hline \multicolumn{6}{|l|}{ GO_TRANSL } \\
\hline \multicolumn{6}{|l|}{ ATION_FACT } \\
\hline OR_ACTIVIT & 85 & -0.41632 & -1.84158 & 0.019417 & 0.068772 \\
\hline \multicolumn{6}{|l|}{ Y_RNA_BIND } \\
\hline \multicolumn{6}{|l|}{ ING } \\
\hline \multicolumn{6}{|l|}{ GO_EXORIBO } \\
\hline NUCLEASE_C & 26 & -0.6274 & -1.84234 & 0.001949 & 0.069289 \\
\hline \multicolumn{6}{|l|}{ OMPLEX } \\
\hline \multicolumn{6}{|l|}{ GO_PROTEIN } \\
\hline \multicolumn{6}{|l|}{ _MATURATI } \\
\hline $\begin{array}{l}\text { ON_BY_IRON } \\
\text { _SULFUR_CL }\end{array}$ & 15 & -0.64484 & -1.84377 & 0.004057 & 0.069346 \\
\hline \multicolumn{6}{|l|}{ USTER_TRAN } \\
\hline \multicolumn{6}{|l|}{ SFER } \\
\hline $\begin{array}{c}\text { GO_RRNA_BI } \\
\text { NDING }\end{array}$ & 62 & -0.5234 & -1.83846 & 0.02947 & 0.069931 \\
\hline \multicolumn{6}{|l|}{ GO_CHAPER } \\
\hline ONE_COMPL & 22 & -0.52839 & -1.82641 & 0.009434 & 0.076538 \\
\hline \multicolumn{6}{|l|}{$\mathrm{EX}$} \\
\hline $\begin{array}{l}\text { GO_MRNA_M } \\
\text { ODIFICATION }\end{array}$ & 22 & -0.62497 & -1.82752 & 0.001972 & 0.076843 \\
\hline \multicolumn{6}{|l|}{ GO_FORMATI } \\
\hline \multicolumn{6}{|l|}{ ON_OF_CYTO } \\
\hline $\begin{array}{l}\text { PLASMIC_TR } \\
\text { ANSLATION_ }\end{array}$ & 16 & -0.70601 & -1.82141 & 0 & 0.07933 \\
\hline \multicolumn{6}{|l|}{ INITIATION_ } \\
\hline \multicolumn{6}{|l|}{ COMPLEX } \\
\hline \multicolumn{6}{|l|}{ GO_COTRAN } \\
\hline \multicolumn{6}{|l|}{ SLATIONAL_ } \\
\hline PROTEIN_TA & 99 & -0.72461 & -1.81843 & 0.005988 & 0.08072 \\
\hline \multicolumn{6}{|l|}{ RGETING_TO } \\
\hline \multicolumn{6}{|l|}{ _MEMBRANE } \\
\hline $\begin{array}{c}\text { GO_RNA_SPL } \\
\text { ICING }\end{array}$ & 431 & -0.41768 & -1.81217 & 0.024904 & 0.08327 \\
\hline \multicolumn{6}{|l|}{ GO_EUKARY } \\
\hline $\begin{array}{l}\text { OTIC_48S_PR } \\
\text { EINITIATION }\end{array}$ & 15 & -0.73597 & -1.81246 & 0 & 0.084235 \\
\hline _COMPLEX & & & & & \\
\hline GO_MITOCH & & & & & \\
\hline ONDRIAL_RE & 95 & -0.50974 & -1.80943 & 0.044444 & 0.084279 \\
\hline SPIRATORY_ & & & & & \\
\hline
\end{tabular}




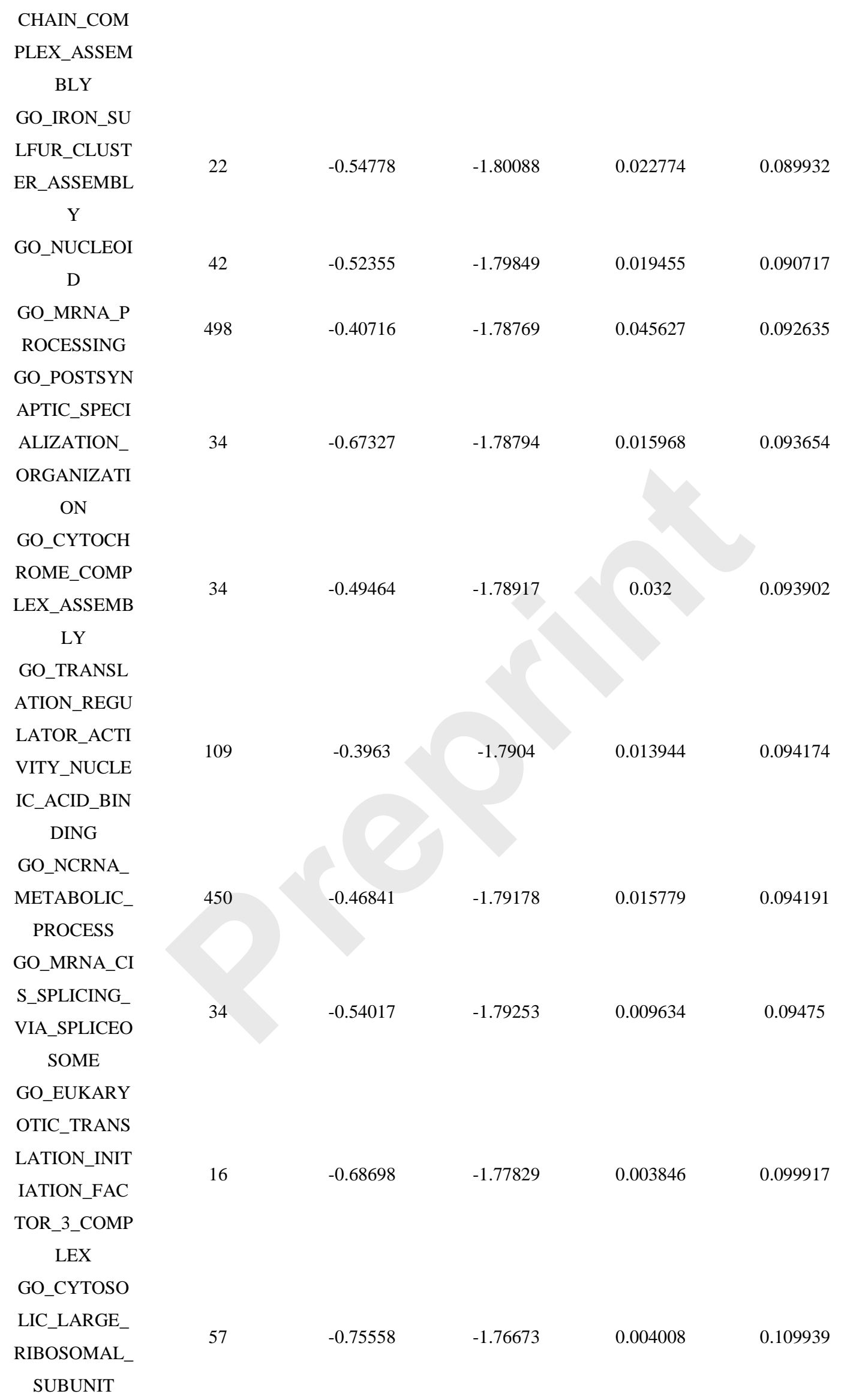




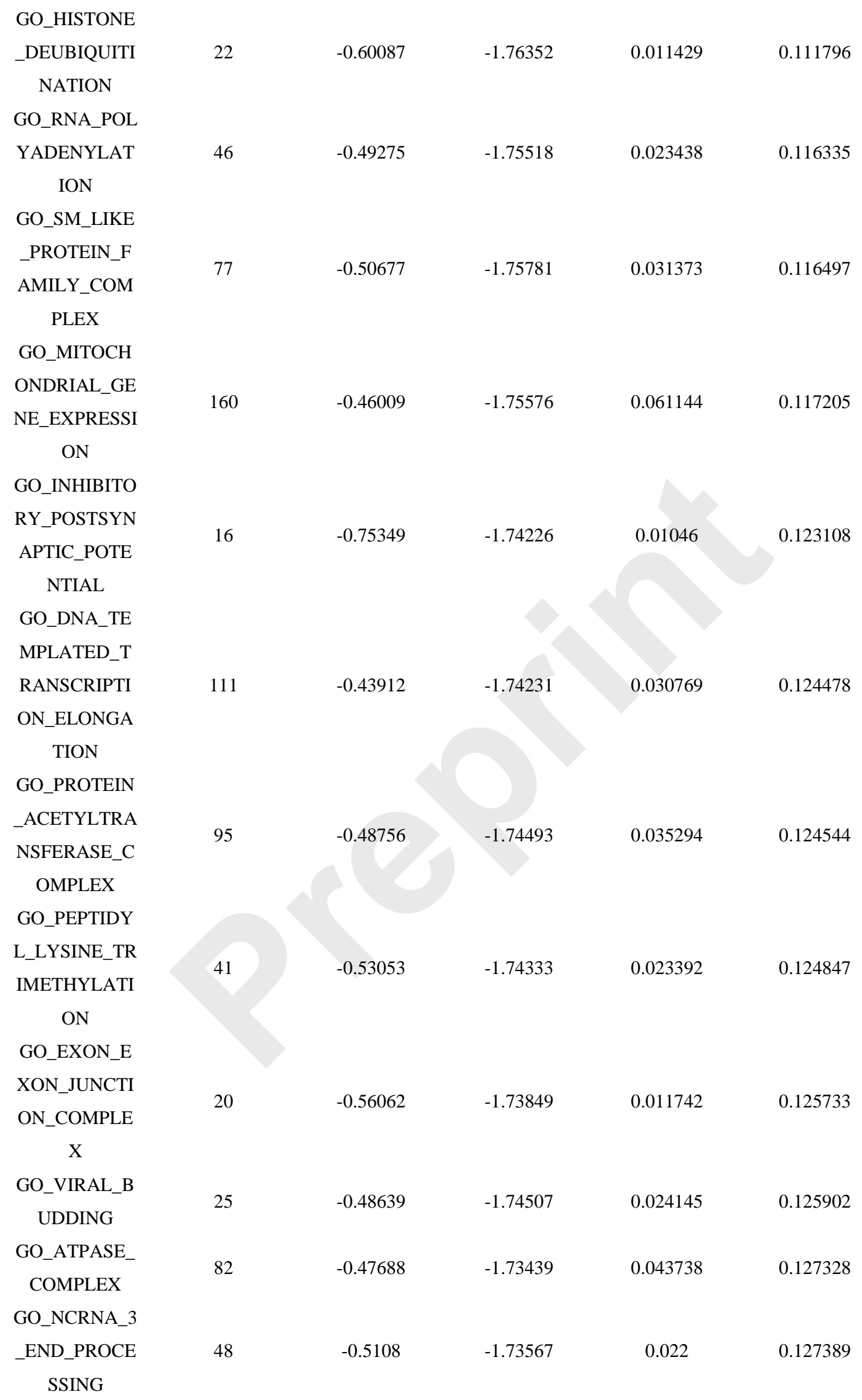




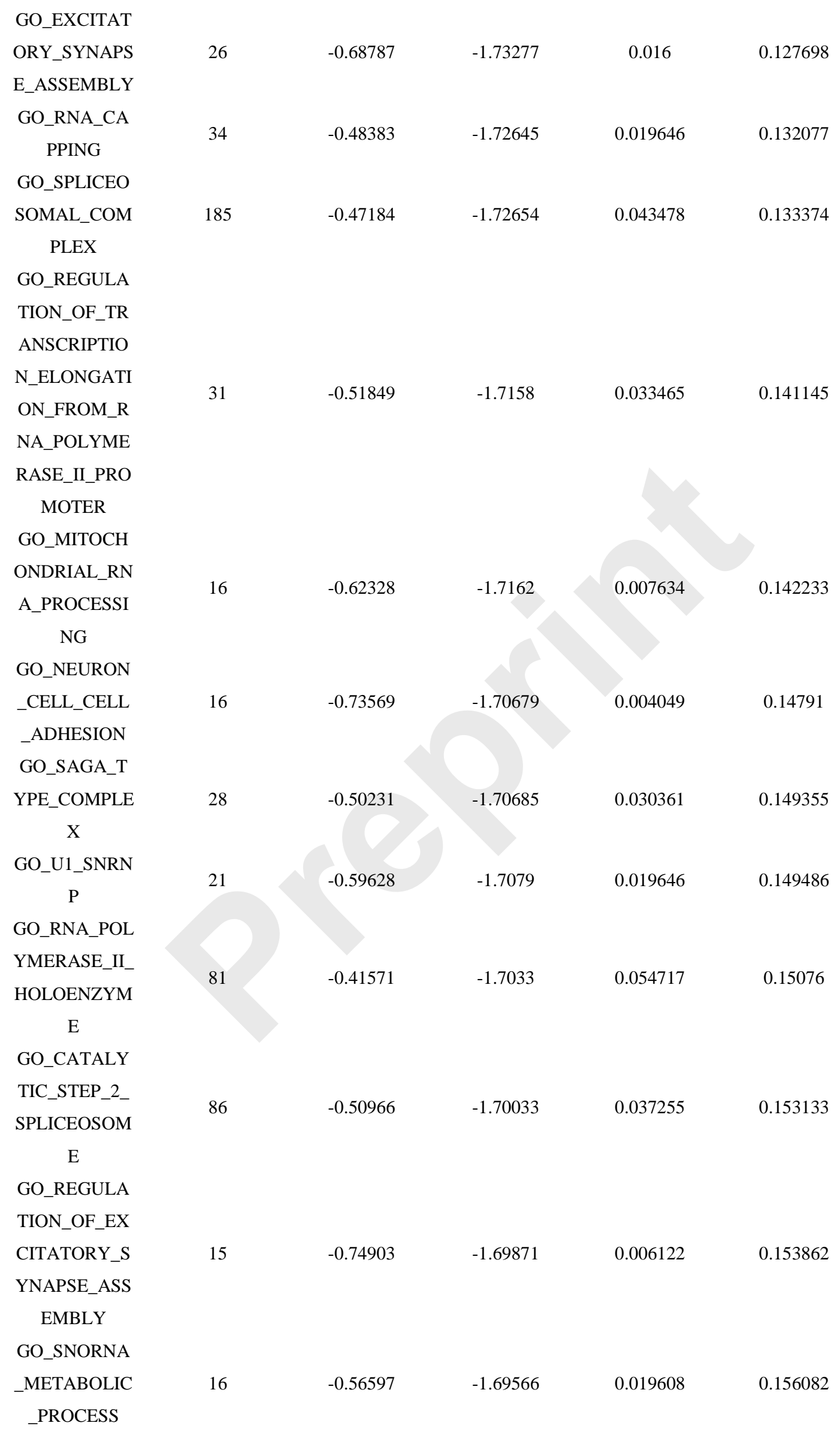




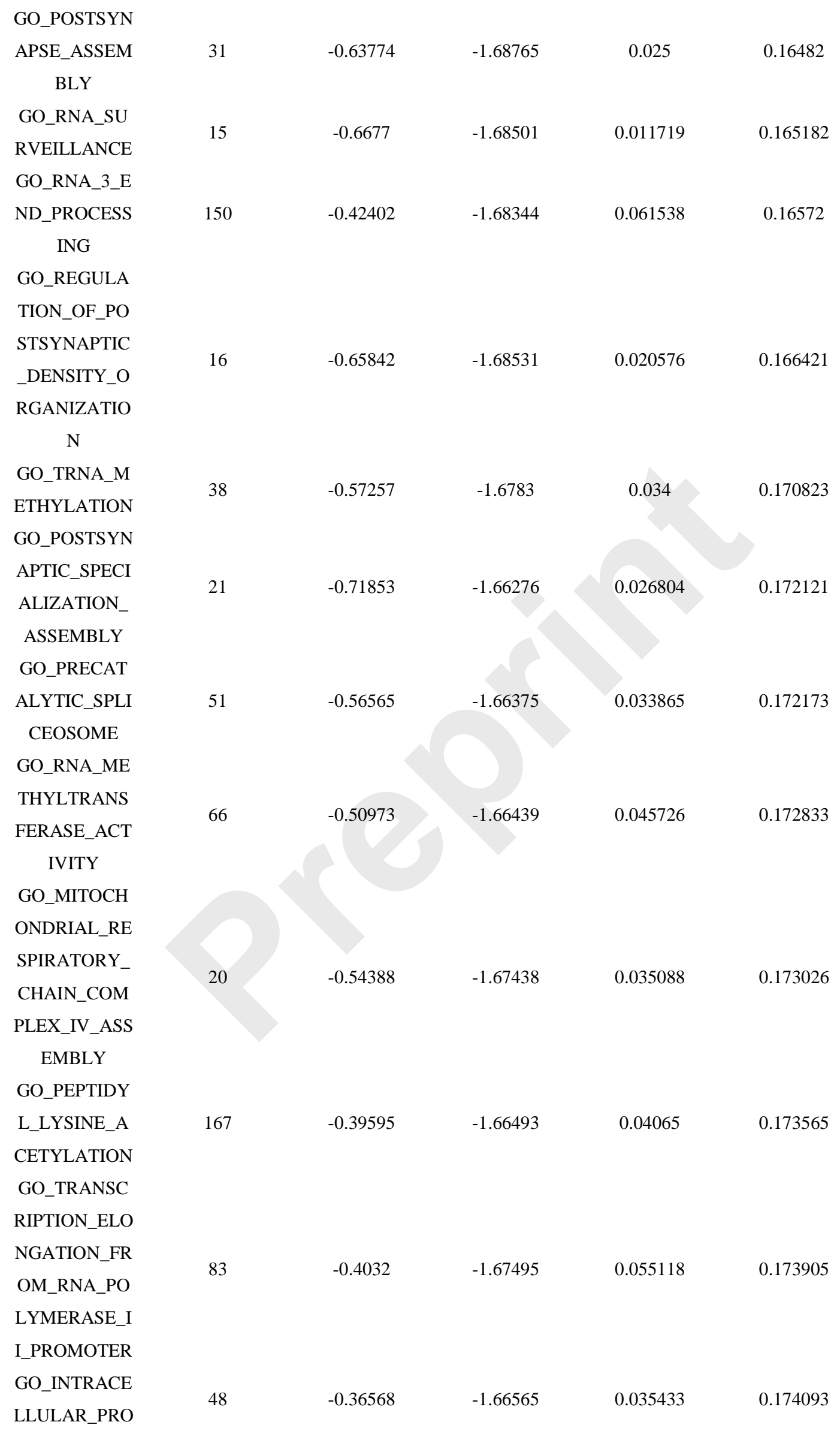


TEIN_TRANS

MEMBRANE_

TRANSPORT

GO_PEPTIDY

L_LYSINE_DI

METHYLATI

18

$-1.67236$

0.009804

0.174156

ON

GO_METHYL

TRANSFERAS

113

$-0.48412$

$-1.66651$

0.083495

0.174404

E_COMPLEX

GO_TRNA_T

HREONYLCA

RBAMOYLAD

ENOSINE_ME

16

$-0.5861$

$-1.66691$

0.016

0.175365

TABOLIC_PR

OCESS

GO_PRC1_CO MPLEX

GO_SNORNA BINDING

GO_MITOCH

ONDRIAL_TR

0.176609

ANSLATION

GO_REGULA

TION_OF_TR

ANSLATIONA

$-1.6549$

0.025097

0.178565

L_FIDELITY

GO_TRANSC

RIPTION_ELO

NGATION_FR

OM_RNA_PO

$-0.51936$

$-1.65576$

0.032319

0.178865

LYMERASE_I

_PROMOTER

GO_BITTER_

TASTE_RECE

PTOR_ACTIVI

22

$-0.6223$

$-1.65666$

0.023576

0.179081

TY

GO_MLL1_2_ COMPLEX

29

$-0.54225$

$-1.65071$

0.052734

0.183087

GO_NEGATIV

E_REGULATI

ON_OF_MRN

21

$-0.52078$

$-1.64912$

0.017578

0.183835 





ASE_ACTIVIT

GO_HISTONE

_H4_ACETYL

64

$-0.41691$

$-1.6288$

0.065606

0.19608

ATION

GO_TRANSL

ATIONAL TE

104

$-0.45739$

$-1.62373$

0.107422

0.196353

RMINATION

GO_SPLICEO

SOMAL_TRI

SNRNP_COM

31

$-0.55981$

$-1.62443$

0.060784

0.196743

PLEX

GO_REGULA

TION_OF_MR

NA_PROCESS

$-0.36978$

$-1.63245$

0.068359

0.196874

ING

GO_RNA_ME

THYLATION

78

$-1.6252$

0.072978

0.197018

GO_U2_SNRN

$\mathrm{P}$

21

$-0.52034$

$-1.6258$

0.041339

0.197573

GO_NEGATIV

E_REGULATI

ON_OF_UBIQ

UITIN_DEPEN

48

$-0.36478$

$-1.62615$

0.043137

0.198445

DENT_PROTE

IN_CATABOL

IC_PROCESS

GO_REGULA

TION_OF_MR

NA_SPLICING

$-0.38697$

$-1.61917$

0.043137

0.198493

VIA_SPLICE

OSOME

GO_MITOCH

ONDRIAL_TR

ANSLATIONA

89

$-0.49126$

$-1.61595$

0.094488

0.201714

L_TERMINAT

ION

GO_RETROG

RADE_TRAN

SPORT_ENDO

87

$-0.35713$

$-1.61477$

0.068136

0.202048

SOME_TO_G

OLGI

GO_N_TERMI

NAL_PROTEI

29

$-0.46342$

$-1.61196$

0.042389

0.204756 


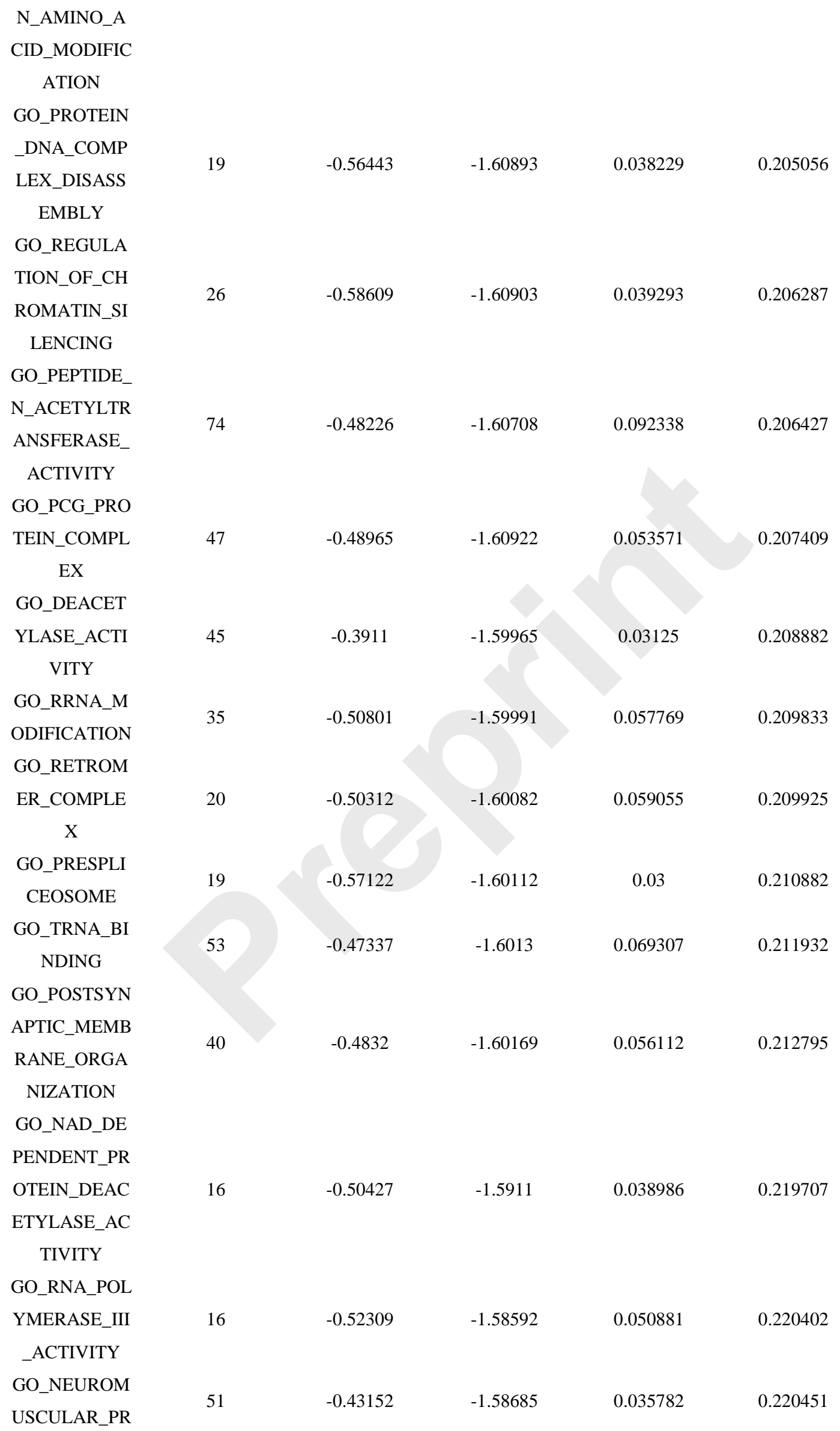




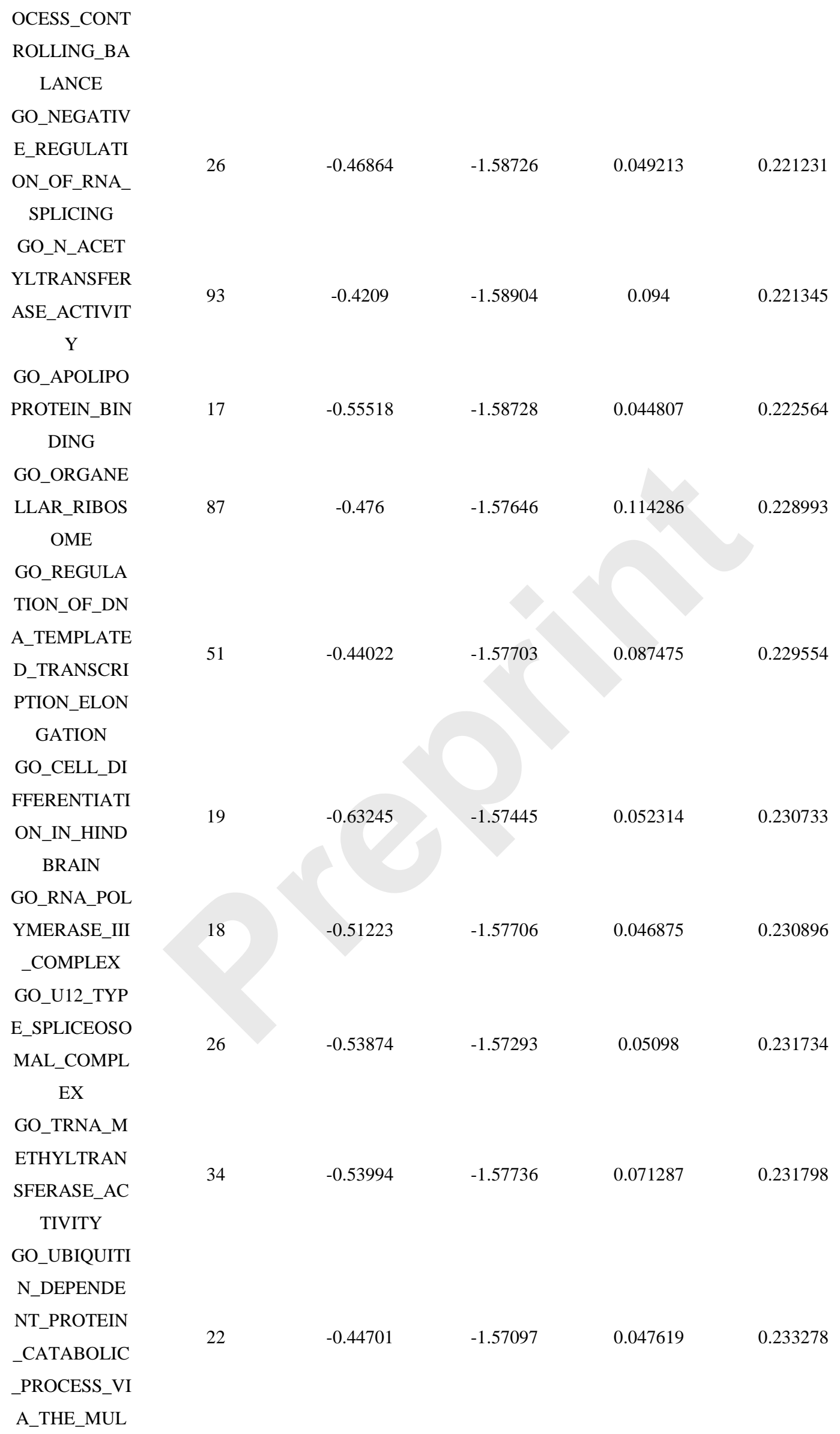


TIVESICULA

R_BODY_SOR

TING_PATHW

AY

GO_PROTEIN

_TRANSMEM

BRANE_IMPO

RT_INTO_INT

$-0.40029$

$-1.56656$

0.064516

0.235804

RACELLULA

R_ORGANEL

LE

GO_CEREBEL

LAR_PURKIN

JE_CELL_LA

24

$-0.493$

$-1.56676$

0.047035

0.236842

YER_DEVEL

OPMENT

GO_TRANSC

RIPTION_INIT

IATION_FRO

M_RNA_POL

37

$-0.4606$

$-1.56746$

0.073585

0.237217

YMERASE_I

PROMOTER

GO_PROTEIN

ACYLATION

$-0.32934$

$-1.56332$

0.067485

0.23928

GO_NEGATIV

E_REGULATI

ON_OF_TRAN

SCRIPTION_R

$-0.482$

$-1.56152$

0.018036

0.240552

EGULATORY

_REGION_DN

A_BINDING

GO_CEREBEL

LAR_CORTE

X_FORMATIO

21

$-0.58637$

$-1.55994$

0.054902

0.241553

$\mathrm{N}$

GO_MITOCH

ONDRIAL_LA

RGE_RIBOSO

57

$-0.49032$

$-1.55512$

0.108738

0.247431

MAL_SUBUNI

$\mathrm{T}$

GO_POSITIVE

REGULATIO

N_OF_TOR_SI

$-0.36738$

$-1.55186$

0.056974

0.248242 
GO_CLEAVA

GE_INVOLVE

D_IN_RRNA_

$-0.5857$

$-1.55313$

0.058939

0.249093

PROCESSING

GO_REGULA

TION_OF_RN

138

$-0.35167$

$-1.55197$

0.083499

0.249457

A_SPLICING 
Table S4. Enriched KEGG pathways in high risk group

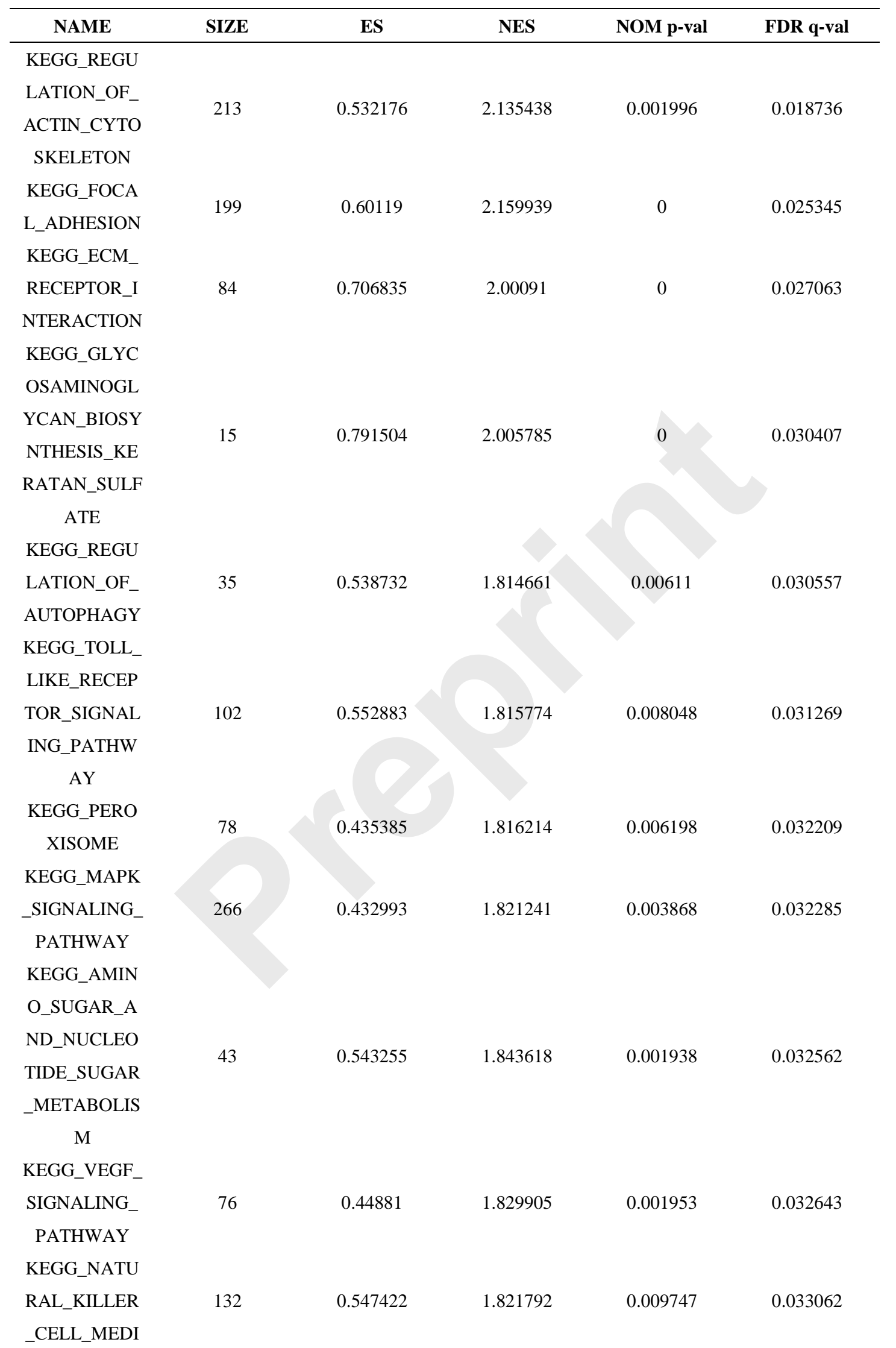


ATED_CYTO

TOXICITY

KEGG_STAR

CH_AND_SU

CROSE_MET

0.540293

1.796439

0.033358

ABOLISM

KEGG_INTES

TINAL_IMMU

NE_NETWOR

45

0.769699

1.834458

0.003846

0.03362

K_FOR_IGA_

PRODUCTION

KEGG_VIRAL

MYOCARDI

68

0.591547

1.823457

0.017045

0.033639

TIS

KEGG_RENA

L_CELL_CAR

69

0.439259

1.830185

0.008197

0.033711

CINOMA

KEGG_PATH

OGENIC_ESC

HERICHIA_C

56

0.489727

1.844087

0.009709

0.033931

OLI_INFECTI

ON

KEGG_B_CEL

L_RECEPTOR

_SIGNALING_

75

0.553006

1.7975

0.029644

0.034212

PATHWAY

KEGG_GALA

CTOSE_MET

0.546625

1.800383

0.005725

0.034318

ABOLISM

KEGG_COMP

LEMENT_AN

D_COAGULA

TION_CASCA

DES

KEGG_CYTO

KINE_CYTOK

INE_RECEPT

263

0.59799

1.871848

0.003759

0.035106

OR_INTERAC

TION

KEGG_TYPE_

I_DIABETES_ MELLITUS

KEGG_LEUK OCYTE_TRA 
NSENDOTHE

LIAL_MIGRA

TION

KEGG_SYSTE

MIC_LUPUS_

ERYTHEMAT

56

0.769012

1.880306

0.003846

0.035923

OSUS

KEGG_RIG_I_

LIKE_RECEP

TOR_SIGNAL

70

0.482615

1.783497

0.003906

0.035972

ING_PATHW

AY

KEGG_SMAL

L_CELL_LUN

84

0.544594

1.857676

0.010183

0.036378

G_CANCER

KEGG_GLYC

OLYSIS_GLU

CONEOGENE

62

0.465965

1.846569

0.004082

0.036759

SIS

KEGG_LYSOS

OME

121

0.489369

1.894862

0.011928

0.036949

KEGG_ARRH

YTHMOGENI

C_RIGHT_VE

NTRICULAR_

0.560281

1.871955

0

0.037232

CARDIOMYO

PATHY_ARV

$\mathrm{C}$

KEGG_AUTOI

MMUNE_THY

ROID_DISEAS

0.72231

1.881859

0.003891

0.038122

E

KEGG_T_CEL

L_RECEPTOR _SIGNALING_

0.558937

1.93024

0.005929

0.038203

PATHWAY

KEGG_LEISH

MANIA_INFE

69

0.707043

1.847399

0.003914

0.038237

CTION

KEGG_INSUL

IN_SIGNALIN

0.436948

2.037023

0.00207

0.038649

G_PATHWAY

KEGG_NICOT

INATE_AND_

0.6386

1.899029

0.002105

0.038769 


\begin{tabular}{|c|c|c|c|c|c|}
\hline \multicolumn{6}{|l|}{ NICOTINAMI } \\
\hline \multicolumn{6}{|l|}{ DE_METABO } \\
\hline \multicolumn{6}{|l|}{ LISM } \\
\hline \multicolumn{6}{|l|}{ KEGG_PENT } \\
\hline $\begin{array}{l}\text { OSE_PHOSPH } \\
\text { ATE_PATHW }\end{array}$ & 26 & 0.474623 & 1.772345 & 0.00998 & 0.038914 \\
\hline \multicolumn{6}{|l|}{$\mathrm{AY}$} \\
\hline \multicolumn{6}{|l|}{ KEGG_CELL_ } \\
\hline $\begin{array}{l}\text { ADHESION_ } \\
\text { MOLECULES }\end{array}$ & 131 & 0.615927 & 1.919338 & 0.003929 & 0.039135 \\
\hline \multicolumn{6}{|l|}{ _CAMS } \\
\hline \multicolumn{6}{|l|}{ KEGG_PATH } \\
\hline WAYS_IN_CA & 324 & 0.451288 & 1.938272 & 0.003929 & 0.039624 \\
\hline \multicolumn{6}{|l|}{ NCER } \\
\hline \multicolumn{6}{|l|}{ KEGG_GLYC } \\
\hline $\begin{array}{c}\text { OSAMINOGL } \\
\text { YCAN_DEGR } \\
\text { ADATION }\end{array}$ & 21 & 0.60801 & 1.76597 & 0.013645 & 0.040456 \\
\hline \multicolumn{6}{|l|}{ KEGG_HEMA } \\
\hline $\begin{array}{l}\text { TOPOIETIC_C } \\
\text { ELL_LINEAG }\end{array}$ & 85 & 0.643074 & 1.760825 & 0.009542 & 0.041222 \\
\hline $\mathrm{E}$ & & & & & \\
\hline $\begin{array}{c}\text { KEGG_APOPT } \\
\text { OSIS }\end{array}$ & 87 & 0.532123 & 1.899153 & 0.002004 & 0.042294 \\
\hline \multicolumn{6}{|l|}{ KEGG_FC_GA } \\
\hline $\begin{array}{l}\text { MMA_R_MED } \\
\text { IATED_PHAG }\end{array}$ & 96 & 0.495443 & 1.754226 & 0.026477 & 0.042473 \\
\hline \multicolumn{6}{|l|}{ OCYTOSIS } \\
\hline \multicolumn{6}{|l|}{ KEGG_JAK_S } \\
\hline $\begin{array}{l}\text { TAT_SIGNALI } \\
\text { NG_PATHWA }\end{array}$ & \multicolumn{2}{|c|}{ NG_PATHWA } & 1.942243 & 0.003906 & 0.043157 \\
\hline \multicolumn{6}{|l|}{$\mathrm{Y}$} \\
\hline $\begin{array}{c}\text { KEGG_TIGHT } \\
\text { _JUNCTION }\end{array}$ & 132 & 0.38537 & 1.733856 & 0.005837 & 0.044617 \\
\hline \multicolumn{6}{|l|}{ KEGG_PHEN } \\
\hline $\begin{array}{l}\text { YLALANINE_ } \\
\text { METABOLIS }\end{array}$ & 18 & 0.633864 & 1.74082 & 0.003802 & 0.045125 \\
\hline M & & & & & \\
\hline KEGG_TYRO & & & & & \\
\hline SINE_METAB & 42 & 0.51101 & 1.734968 & 0 & 0.045161 \\
\hline OLISM & & & & & \\
\hline $\begin{array}{l}\text { KEGG_HYPE } \\
\text { RTROPHIC_C }\end{array}$ & 82 & 0.500714 & 1.743835 & 0.005629 & 0.04535 \\
\hline
\end{tabular}




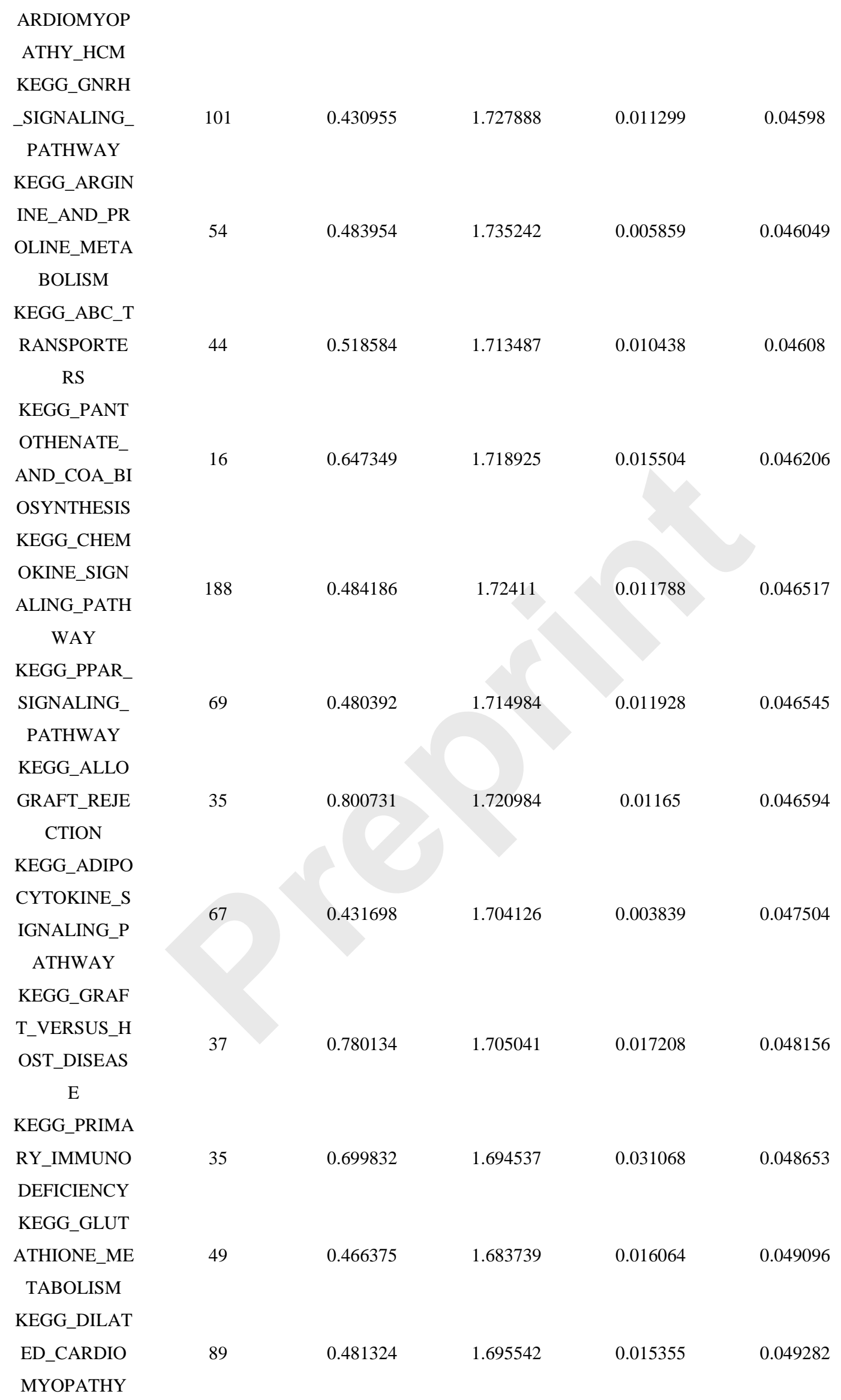




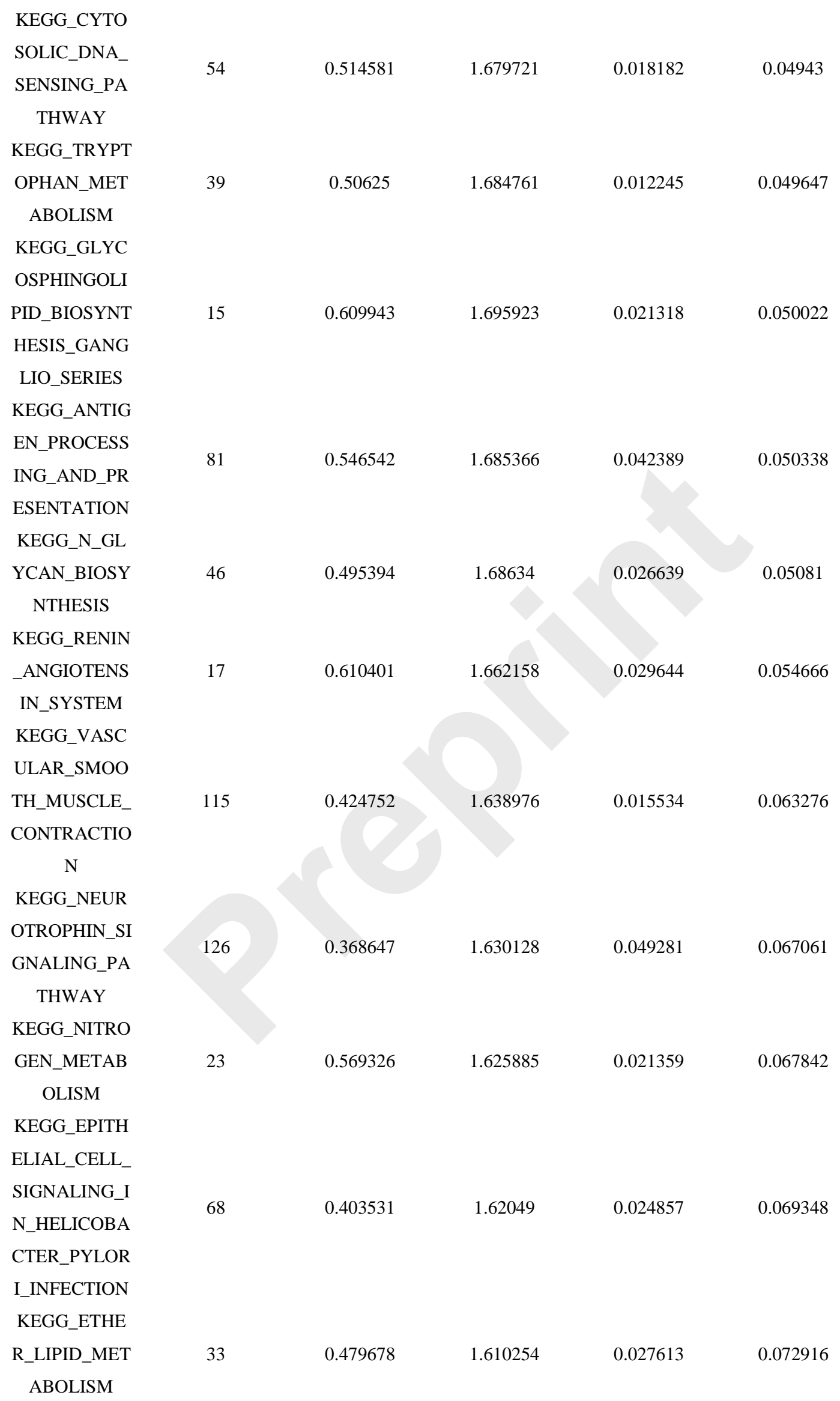




\begin{tabular}{|c|c|c|c|c|c|}
\hline RENS_JUNCT & 73 & 0.421583 & 1.59993 & 0.047722 & 0.074717 \\
\hline \multicolumn{6}{|l|}{ ION } \\
\hline \multicolumn{6}{|l|}{ KEGG_GLYC } \\
\hline \multicolumn{6}{|l|}{ OSAMINOGL } \\
\hline $\begin{array}{l}\text { YCAN_BIOSY } \\
\text { NTHESIS_HE }\end{array}$ & 26 & 0.511454 & 1.601347 & 0.038388 & 0.075111 \\
\hline \multicolumn{6}{|l|}{ PARAN_SULF } \\
\hline \multicolumn{6}{|l|}{ ATE } \\
\hline \multicolumn{6}{|l|}{ KEGG_O_GL } \\
\hline YCAN_BIOSY & 30 & 0.529865 & 1.60279 & 0.029354 & 0.075441 \\
\hline \multicolumn{6}{|l|}{ NTHESIS } \\
\hline $\begin{array}{c}\text { KEGG_AXON } \\
\text { _GUIDANCE }\end{array}$ & 129 & 0.425279 & 1.578991 & 0.048733 & 0.083028 \\
\hline $\begin{array}{c}\text { KEGG_ASTH } \\
\text { MA }\end{array}$ & 28 & 0.722417 & 1.580982 & 0.046 & 0.083357 \\
\hline \multicolumn{6}{|l|}{ KEGG_GLYC } \\
\hline $\begin{array}{l}\text { EROPHOSPH } \\
\text { OLIPID_MET }\end{array}$ & 77 & 0.379531 & 1.575834 & 0.021526 & 0.083478 \\
\hline \multicolumn{6}{|l|}{ ABOLISM } \\
\hline $\begin{array}{c}\text { KEGG_PRION } \\
\text { _DISEASES }\end{array}$ & 35 & 0.478762 & 1.570973 & 0.054 & 0.084876 \\
\hline \multicolumn{6}{|l|}{ KEGG_FC_EP } \\
\hline $\begin{array}{l}\text { SILON_RI_SI } \\
\text { GNALING_PA }\end{array}$ & 79 & 0.417149 & 1.562325 & 0.046243 & 0.087301 \\
\hline \multicolumn{6}{|l|}{ THWAY } \\
\hline \multicolumn{6}{|l|}{ KEGG_PANC } \\
\hline $\begin{array}{c}\text { REATIC_CAN } \\
\text { CER }\end{array}$ & 69 & 0.431012 & 1.563278 & 0.054393 & 0.087892 \\
\hline \multicolumn{6}{|l|}{ KEGG_ACUT } \\
\hline $\begin{array}{c}\text { E_MYELOID_ } \\
\text { LEUKEMIA }\end{array}$ & 57 & 0.414891 & 1.55866 & 0.068136 & 0.087903 \\
\hline \multicolumn{6}{|l|}{ KEGG_TYPE_ } \\
\hline \multicolumn{6}{|l|}{ _MELLITUS } \\
\hline \multicolumn{6}{|l|}{$\begin{array}{l}\text { KEGG_NOD_ } \\
\text { LIKE_RECEP }\end{array}$} \\
\hline \multicolumn{6}{|l|}{ ING_PATHW } \\
\hline \multicolumn{6}{|l|}{ AY } \\
\hline \multicolumn{6}{|l|}{ KEGG_PRIMA } \\
\hline $\begin{array}{l}\text { RY_BILE_ACI } \\
\text { D_BIOSYNTH }\end{array}$ & 16 & 0.587258 & 1.532746 & 0.055441 & 0.097954 \\
\hline ESIS & & & & & \\
\hline
\end{tabular}




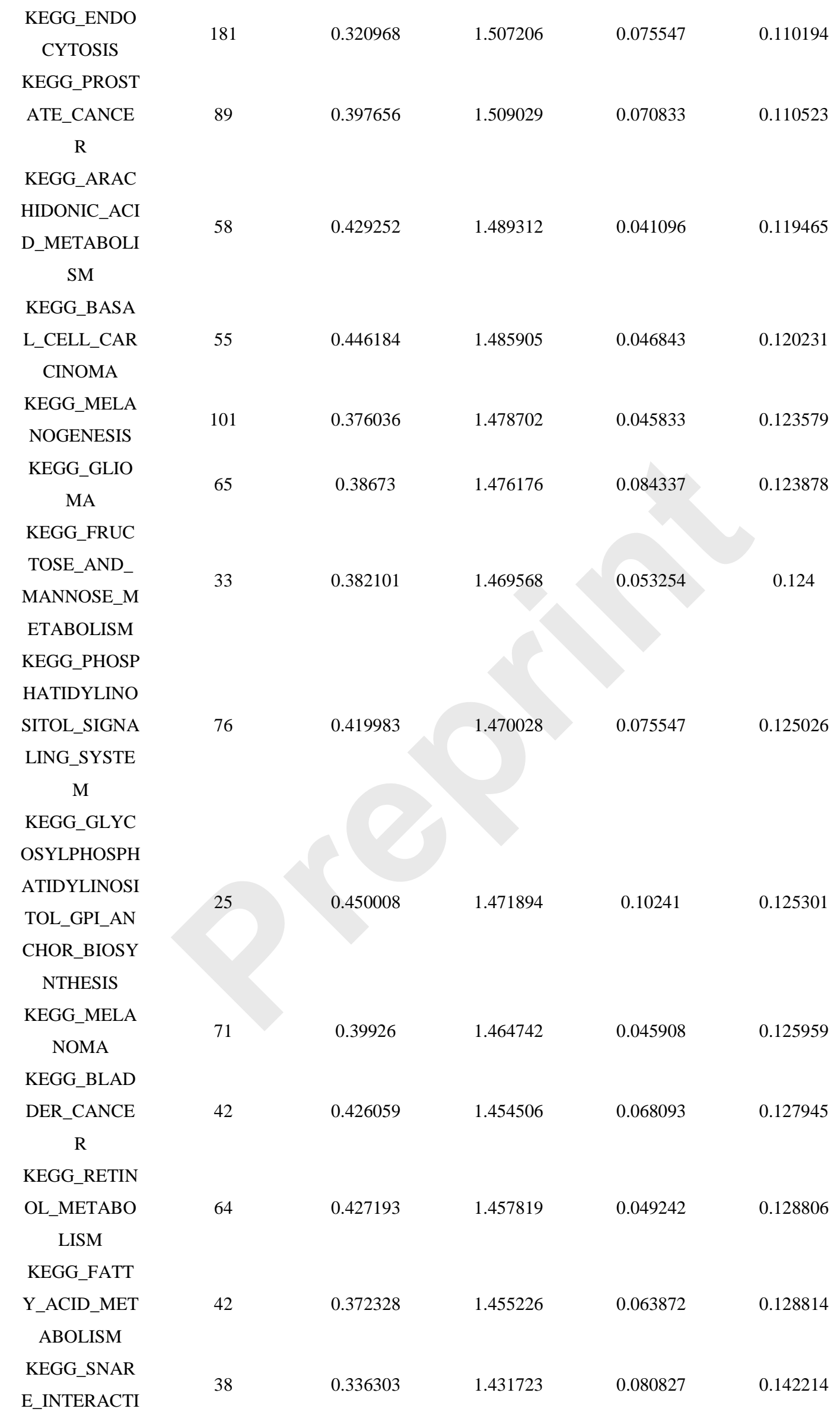




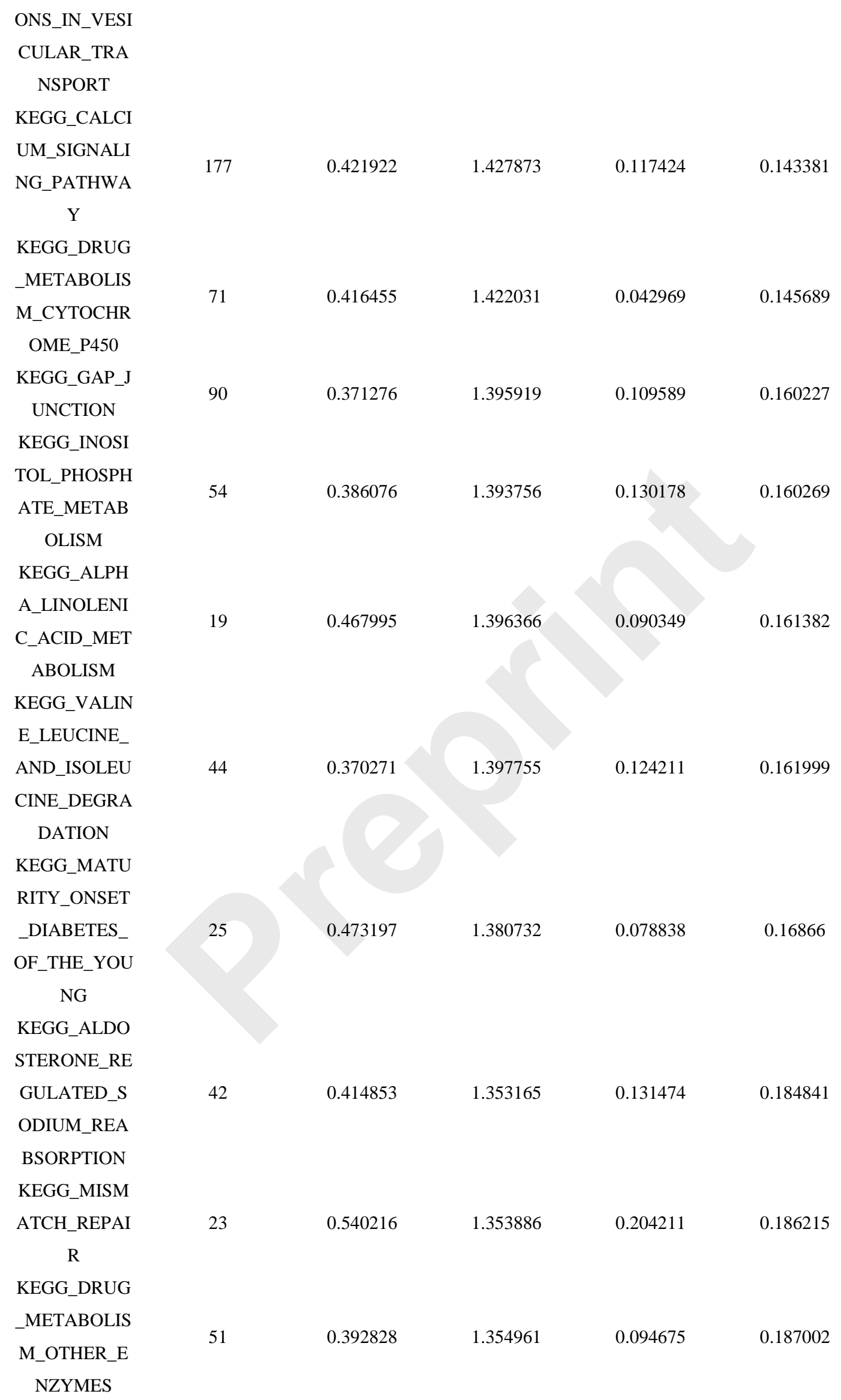


KEGG_BETA_

ALANINE_ME

0.383454

1.340556

0.141717

0.19298

TABOLISM

KEGG_ERBB_

SIGNALING

87

0.335174

1.326931

0.162162

0.202677

PATHWAY

KEGG_PURIN

E_METABOLI

154

0.291601

1.324655

0.106509

0.203209

$\mathrm{SM}$

KEGG_WNT_

SIGNALING_

150

0.304075

1.306515

0.133056

0.216372

PATHWAY

KEGG_META

BOLISM_OF_

XENOBIOTIC

69

0.380683

1.294113

0.120921

0.224856

S_BY_CYTOC

HROME_P450

KEGG_GLYC

OSPHINGOLI

PID_BIOSYNT

HESIS_LACT

26

0.407436

1.28775

0.150476

0.228836

O_AND_NEO

LACTO_SERI

ES

KEGG_OTHE

R_GLYCAN_

DEGRADATI

0.484077

1.279699

0.220408

0.233321

ON

KEGG_MTOR

_SIGNALING_

0.315152

1.2739

0.191057

0.233728

PATHWAY

KEGG_HEDG

EHOG_SIGNA

LING_PATHW

0.36064

1.275143

0.141414

0.234884 
Table S5. Enriched KEGG pathways in low risk group

\begin{tabular}{|c|c|c|c|c|c|}
\hline NAME & SIZE & ES & NES & NOM p-val & FDR q-val \\
\hline $\begin{array}{c}\text { KEGG_RIBOS } \\
\text { OME }\end{array}$ & 88 & -0.79292 & -1.87133 & 0 & 0.115899 \\
\hline $\begin{array}{l}\text { KEGG_RNA_P } \\
\text { OLYMERASE }\end{array}$ & 29 & -0.53494 & -1.77905 & 0.01232 & 0.126753 \\
\hline $\begin{array}{c}\text { KEGG_SPLIC } \\
\text { EOSOME }\end{array}$ & 127 & -0.47047 & -1.72958 & 0.054326 & 0.128102 \\
\hline $\begin{array}{l}\text { KEGG_TERPE } \\
\text { NOID_BACKB } \\
\text { ONE_BIOSYN }\end{array}$ & 15 & -0.68308 & -1.68396 & 0.018987 & 0.135814 \\
\hline THESIS & & & & & \\
\hline $\begin{array}{l}\text { KEGG_SELEN } \\
\text { OAMINO_ACI } \\
\text { D_METABOLI }\end{array}$ & 25 & -0.46771 & -1.59004 & 0.052941 & 0.169369 \\
\hline SM & & & & & \\
\hline $\begin{array}{c}\text { KEGG_RNA_ } \\
\text { DEGRADATI } \\
\text { ON }\end{array}$ & 59 & -0.46737 & -1.59005 & 0.090361 & 0.203243 \\
\hline
\end{tabular}




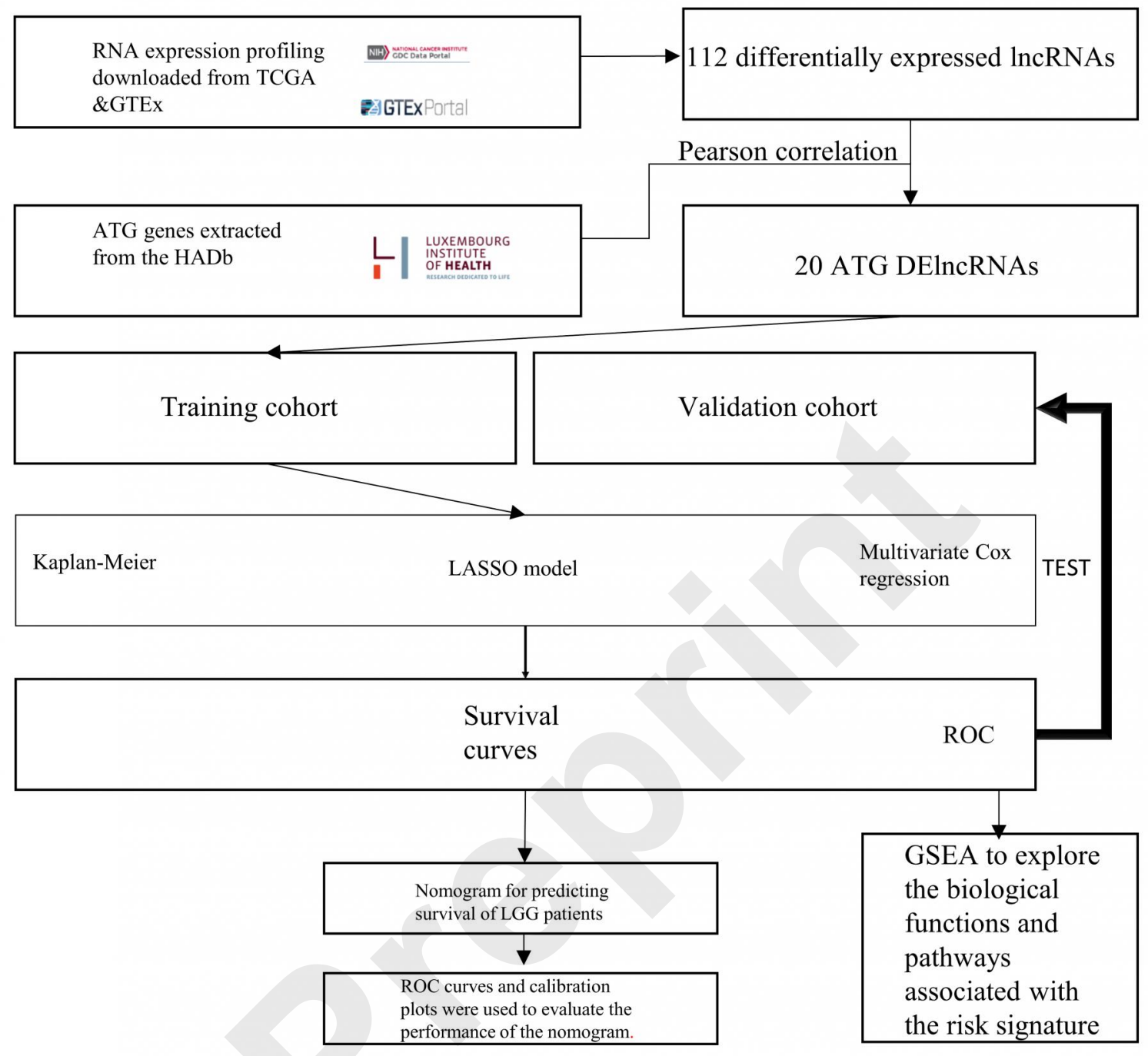

Flow chart of study design. 
a

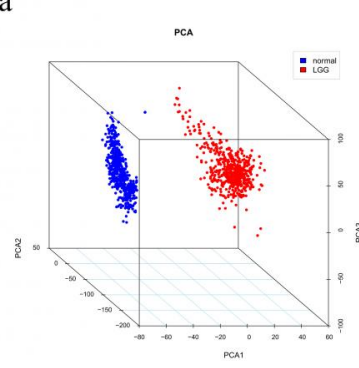

b

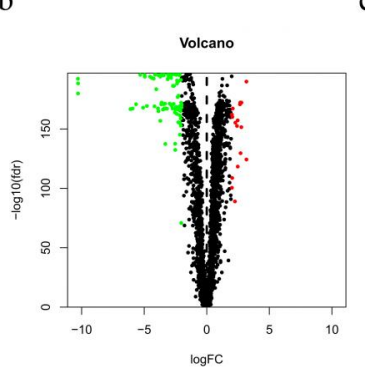

d



c
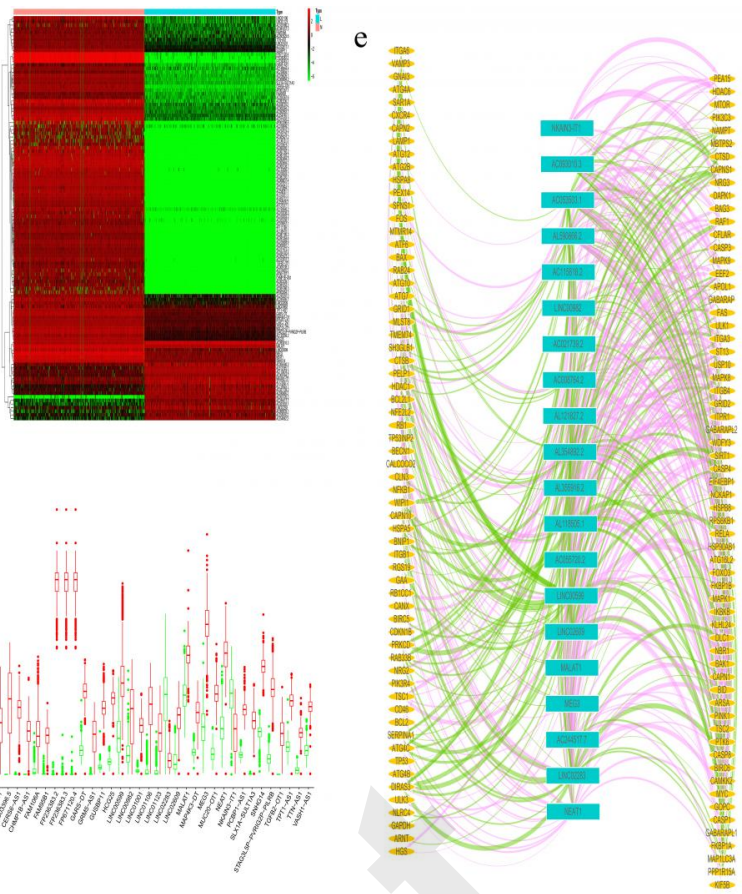

Screening of IncRNAs used for constructing the risk signature for lower-grade gliomas (LGG). 
a

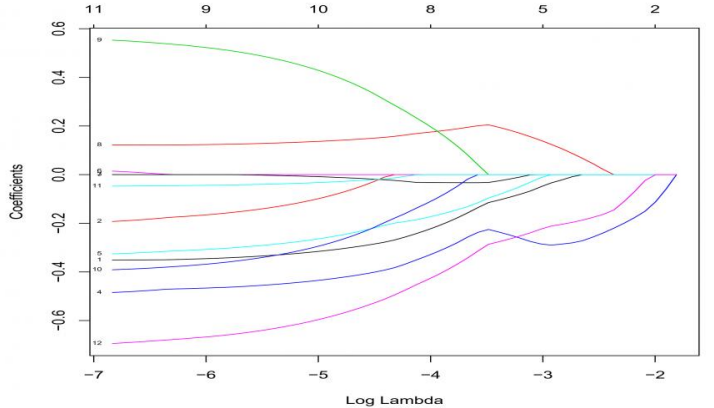

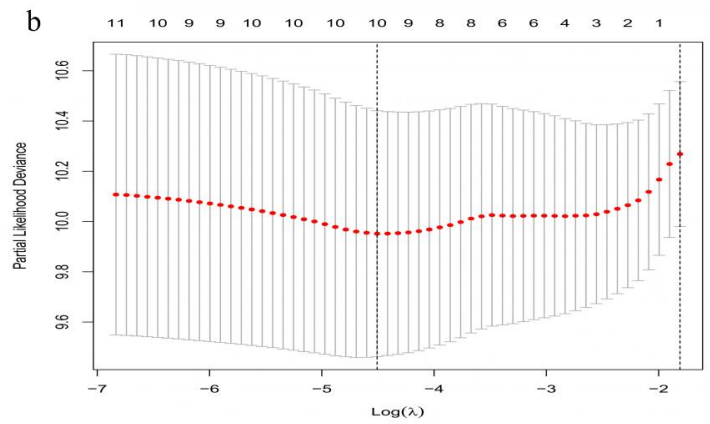

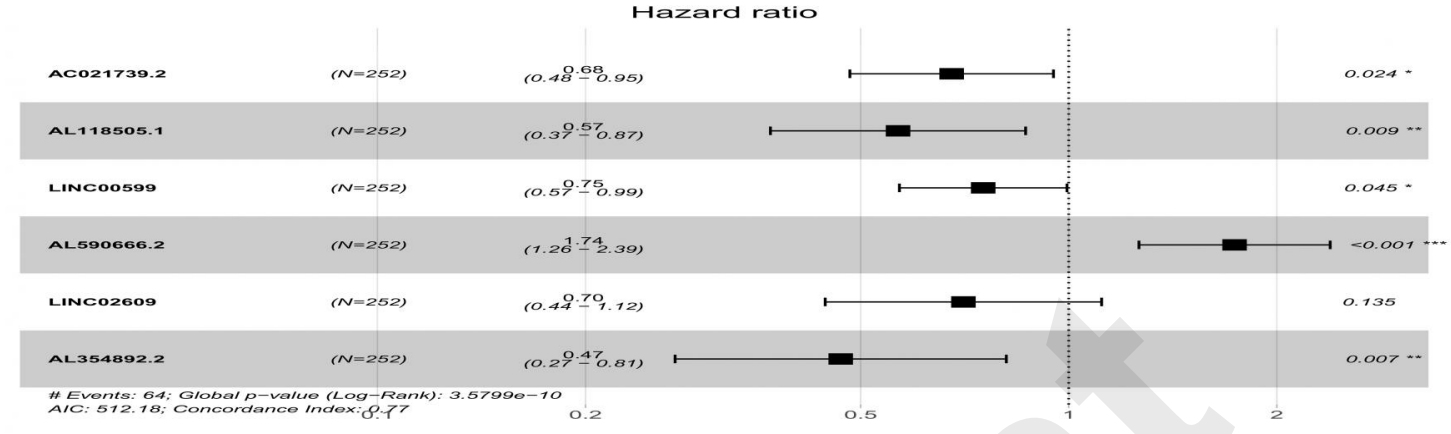

Identification of the autophagy-related differentially expressed IncRNAs (ATG DEIncRNA). 
a
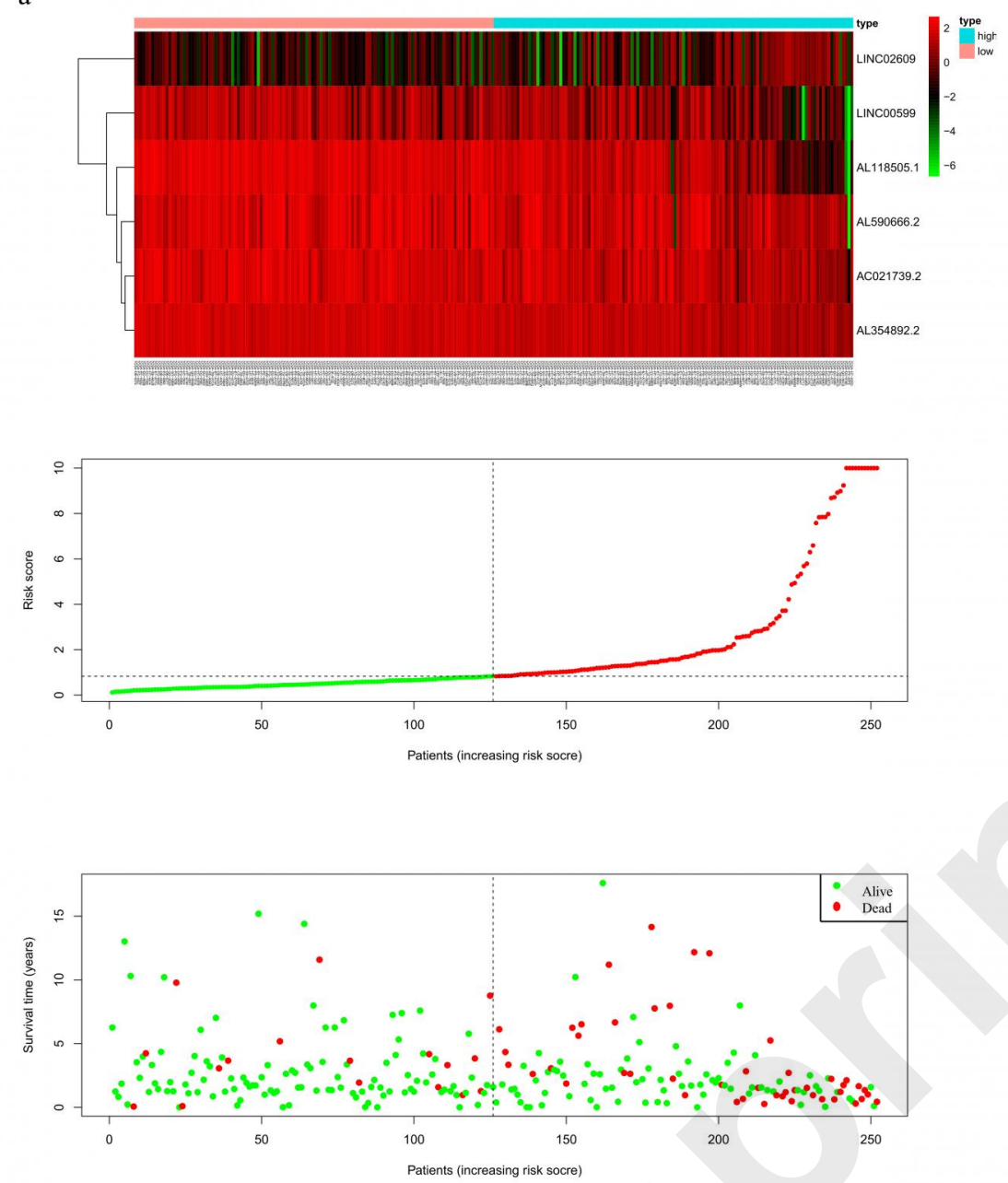

$\mathrm{b}$

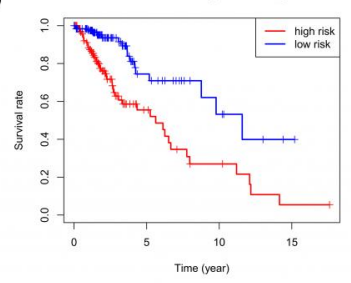

c

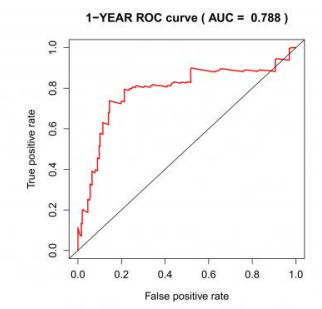

d
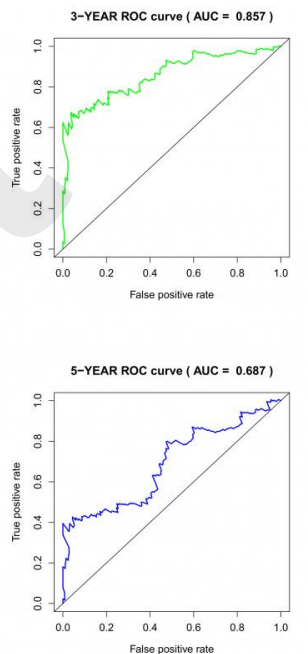

Characteristics of the autophagy-related differentially expressed IncRNAs (ATG DEIncRNA) risk signature in the training cohort. 
a
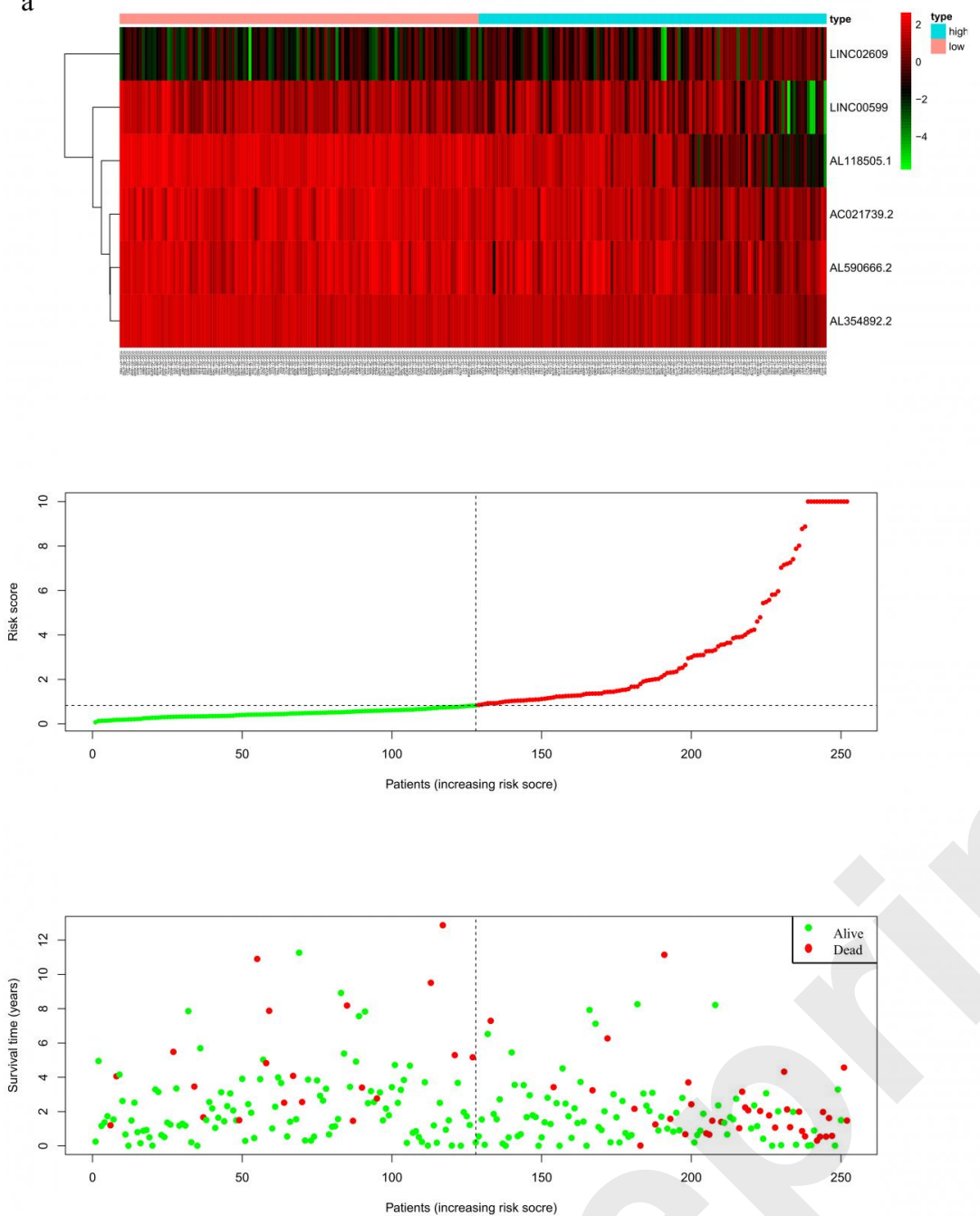

$\mathrm{b}$
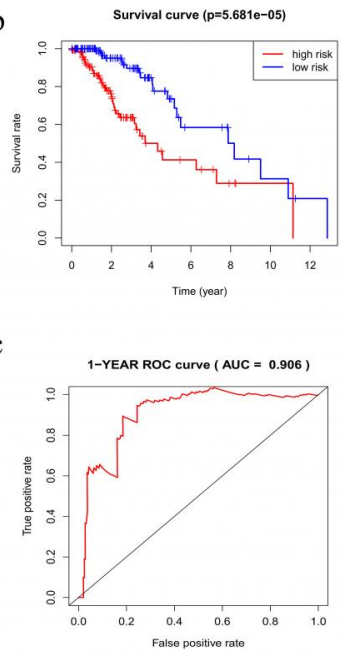

d

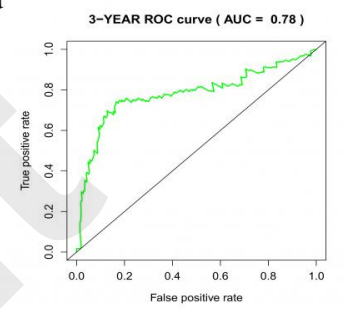

$\mathrm{e}$

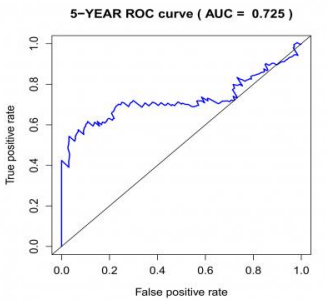

Efficacy of the autophagy-related differentially expressed IncRNAs (ATG DElncRNA) risk signature in the validation cohort. 
a

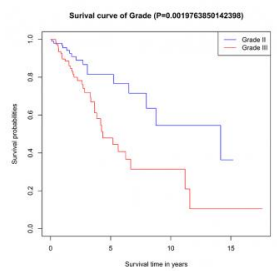

b

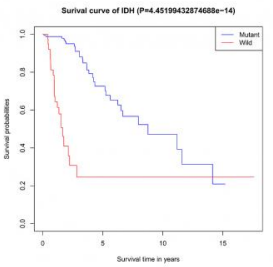

f

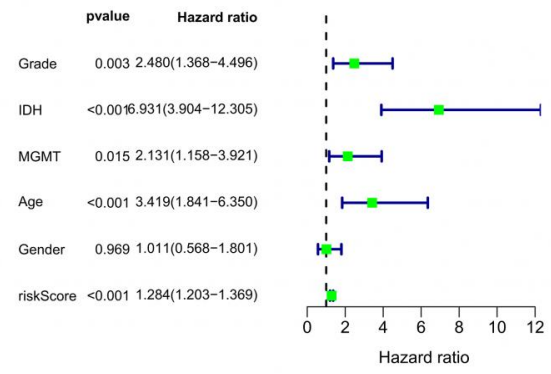

d
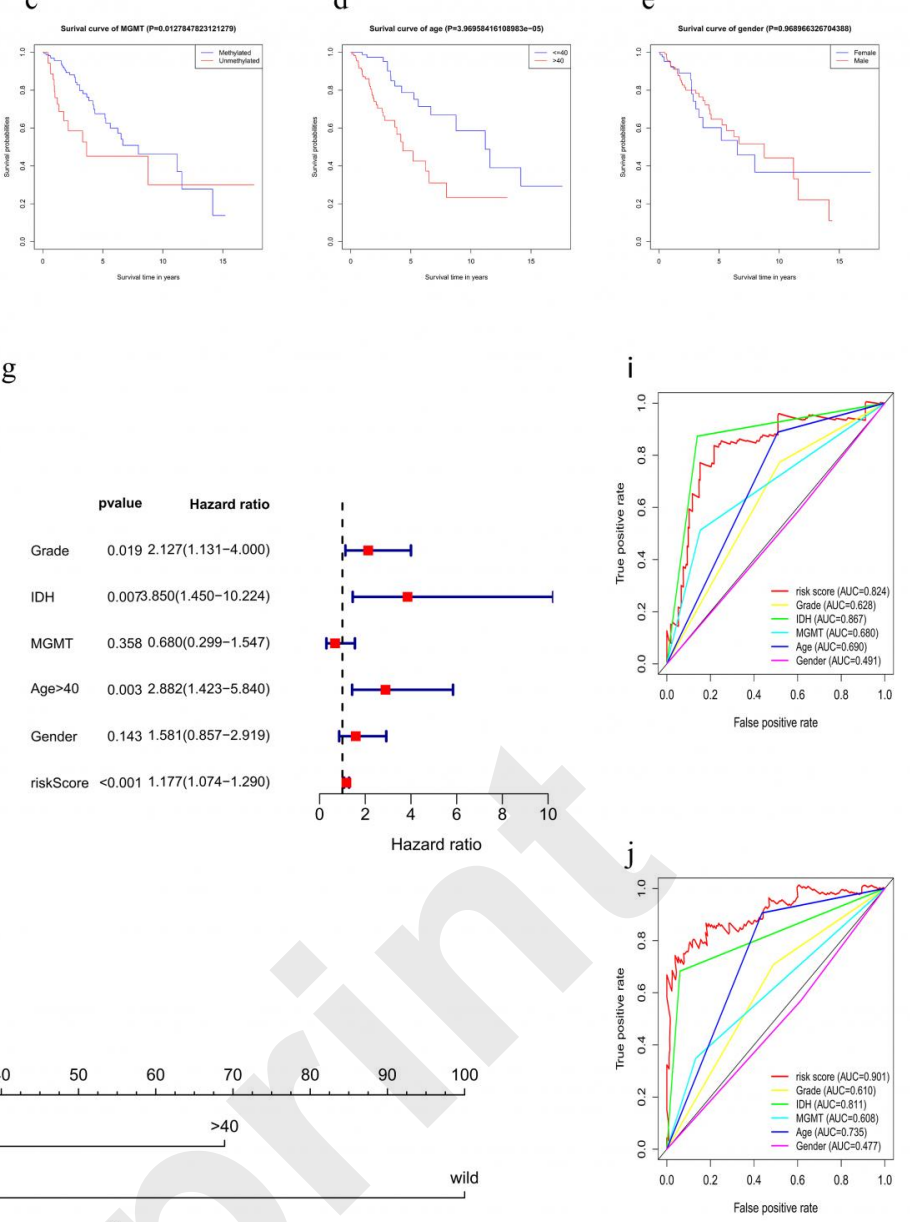

$\mathrm{IDH}$

Grade

MGMT

riskScore

Total Points

1-year survival

3-year survival

5-year survival
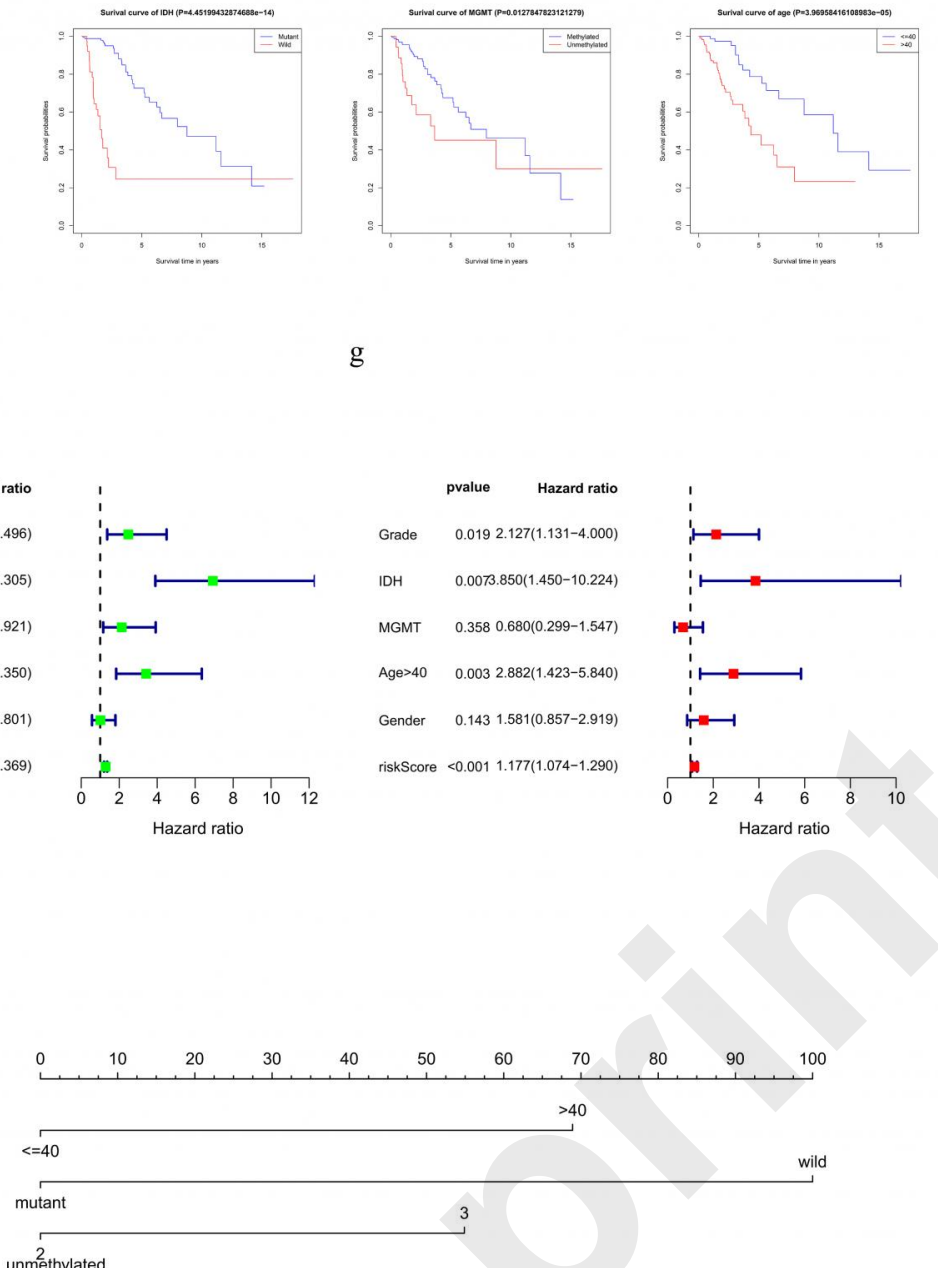

e

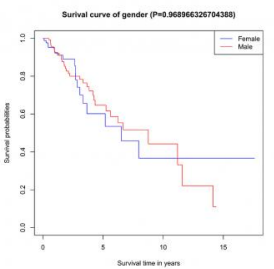

i

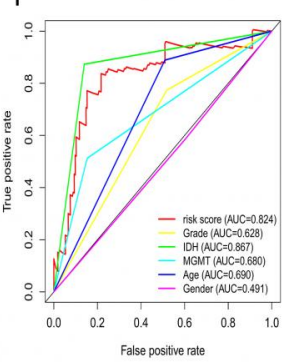

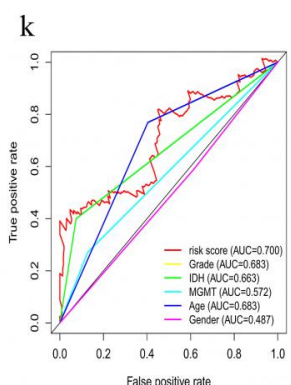

Assessment of the survival prognostic value of the risk signature, as well as clinical (grade, age, and gender) and molecular variables (IDH status and MGMT status) in LGG patients. 
a

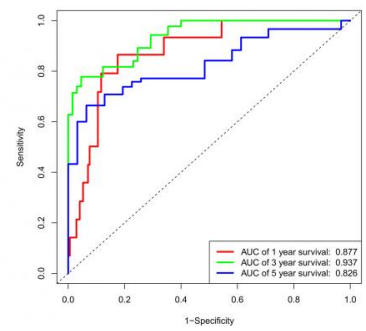

e

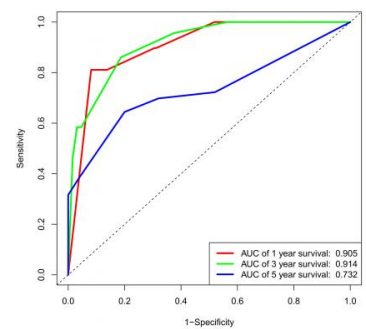

b

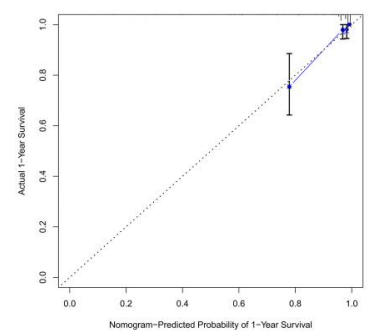

f

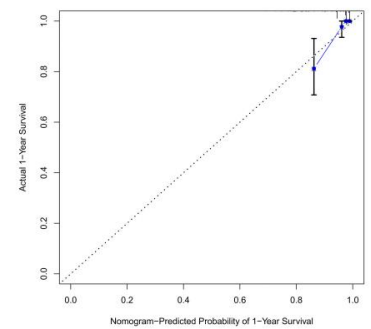

c

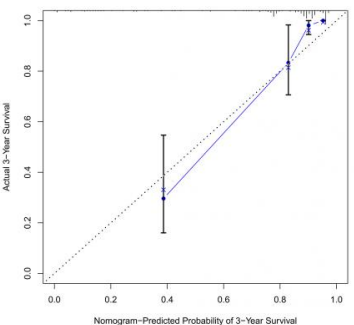

g

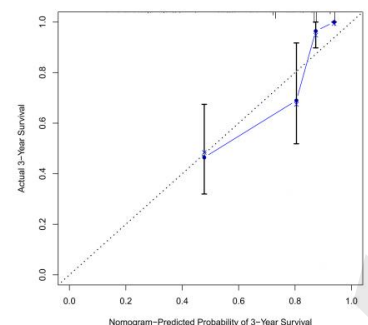

d

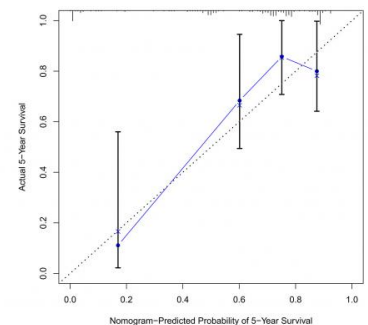

$\mathrm{h}$

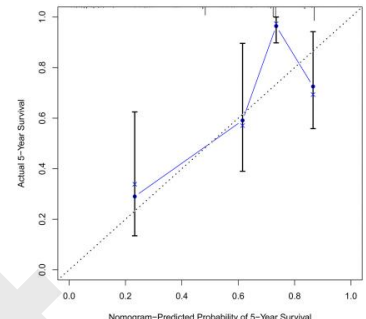

Evaluation of the performance of the nomogram for survival prediction. 




The relationships between the six autophagy-related differentially expressed IncRNAs and their co-expressed genes shown by Sankey diagram 
a

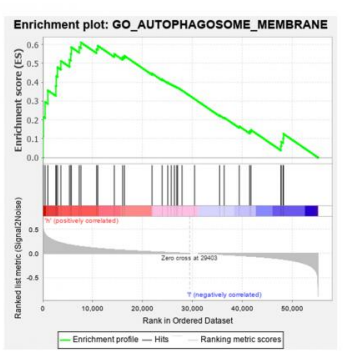

e

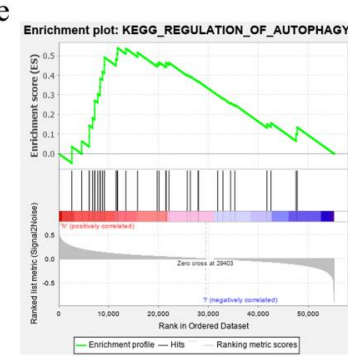

b

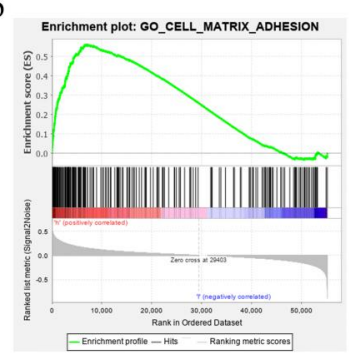

f

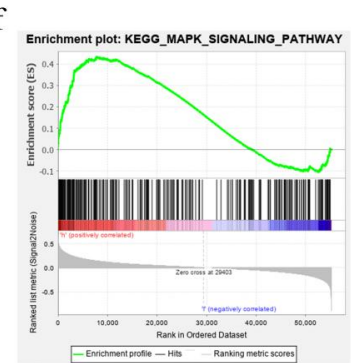

c
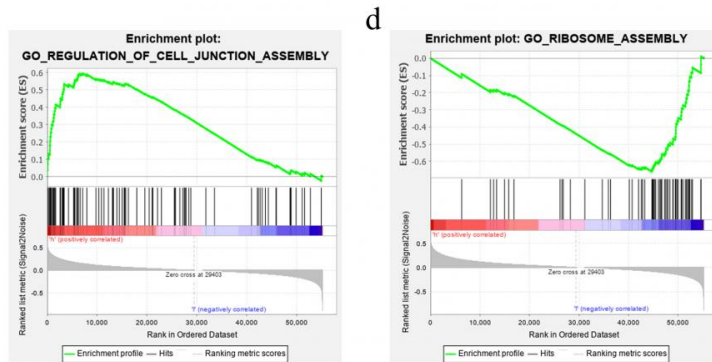

g

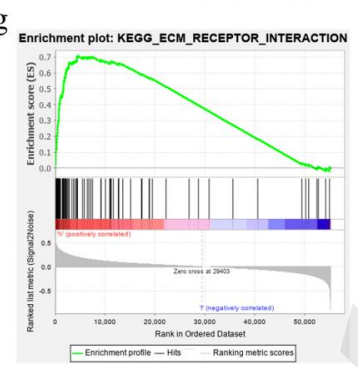

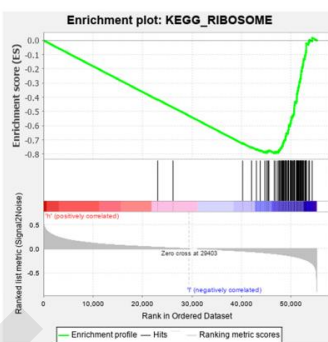

Functional roles of the risk signature by the gene set enrichment analysis (GSEA) 